\title{
Feasibility Study of Developing Alternative Common-Cause Failure Model for Event Assessment
}

Zhegang Ma

James K. Knudsen

John A. Schroeder (Retired)

Curtis L. Smith

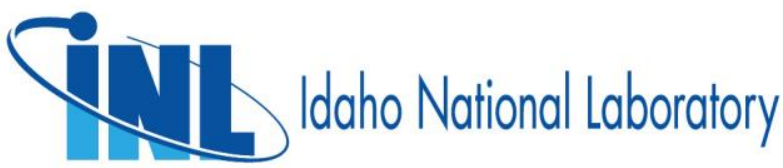




\section{DISCLAIMER}

This information was prepared as an account of work sponsored by an agency of the U.S. Government. Neither the U.S. Government nor any agency thereof, nor any of their employees, makes any warranty, expressed or implied, or assumes any legal liability or responsibility for the accuracy, completeness, or usefulness, of any information, apparatus, product, or process disclosed, or represents that its use would not infringe privately owned rights. References herein to any specific commercial product, process, or service by trade name, trade mark, manufacturer, or otherwise, does not necessarily constitute or imply its endorsement, recommendation, or favoring by the U.S. Government or any agency thereof. The views and opinions of authors expressed herein do not necessarily state or reflect those of the U.S. Government or any agency thereof. 
INL/EXT-21-33376

Revision 1 of INL/LTD-14-33376

\title{
Feasibility Study of Developing Alternative Common- Cause Failure Model for Event Assessment
}

\author{
Zhegang Ma \\ James K. Knudsen \\ John A. Schroeder (Retired) \\ Curtis L. Smith
}

August 2021

Idaho National Laboratory

Idaho Falls, Idaho 83415

http://www.inl.gov

Prepared for the

Division of Risk Analysis

Office of Nuclear Regulatory Research

U.S. Nuclear Regulatory Commission

NRC Agreement Number 31310019N0006

Task Order Number 31310019F0022 
Page intentionally left blank 


\begin{abstract}
This report is a revision of the original report, INL/LTD-14-33376. Distribution of the original report was limited to the Nuclear Regulatory Commission (NRC) only, and the report was not made available to the public. The original report was revised as this report for public distribution.

The report presents a feasibility study of alternative common-cause failure (CCF) models that could be used for event assessment in the Standardized Plant Analysis Risk (SPAR) models. The current CCF model used by the SPAR models is the alpha factor model. The proposed alternative CCF models are the partial alpha factor model and general dependency model. These alternative CCF models are reviewed and compared to the current alpha factor model, with the partial alpha factor model being identified as the preferred CCF model that could be used for event assessment in the SPAR models.
\end{abstract}


Page intentionally left blank 


\section{CONTENTS}

ABSTRACT

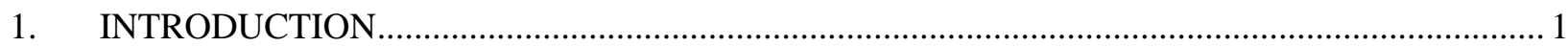

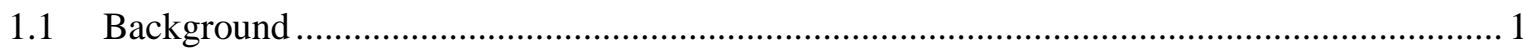

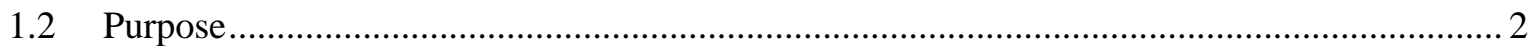

2. REVIEW OF COMMON-CAUSE FAILURE MODELS …........................................................ 3

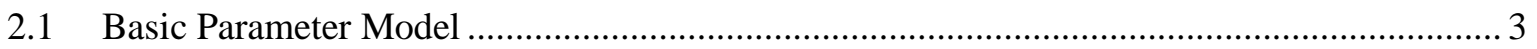

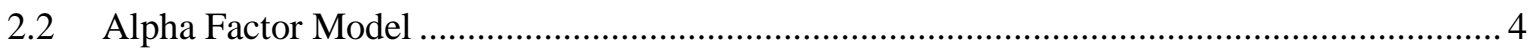

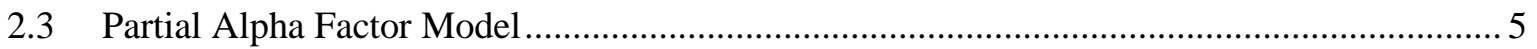

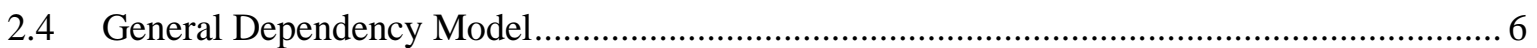

3. FEASIBILITY OF ALTERNATE COMMON-CAUSE FAILURE MODELS ............................ 12

3.1 Strengths of Alternative Common-Cause Failure Models .................................................. 12

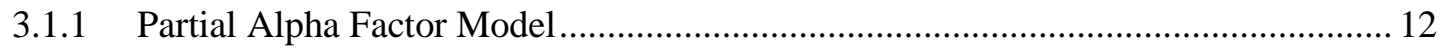

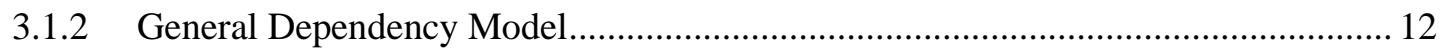

3.2 Limitations of Alternative Common-Cause Failure Models............................................... 13

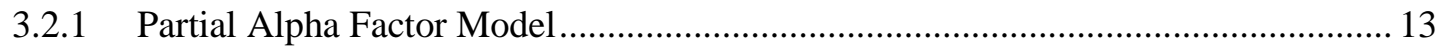

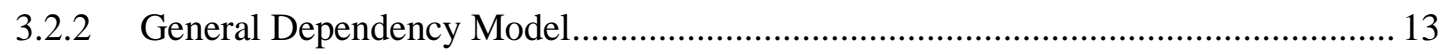

3.3 Common-Cause Failure Model Selected .......................................................................... 14

4. DATA REVIEW FOR PARTIAL ALPHA FACTOR MODEL ….............................................. 15

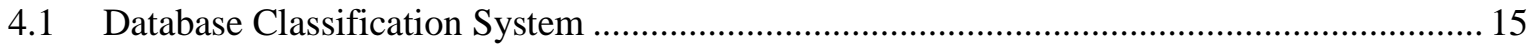

4.2 Existing Common-Cause Failure Data for Partial Alpha Factor Model Parameter

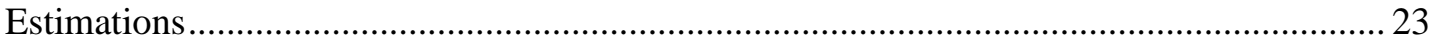

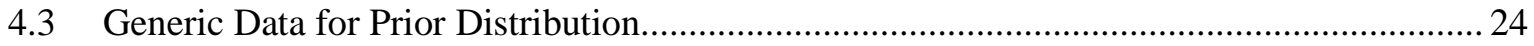

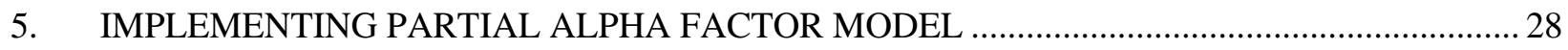

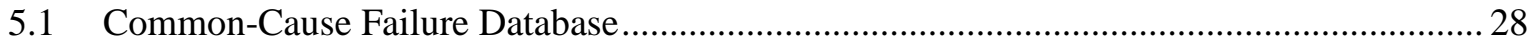

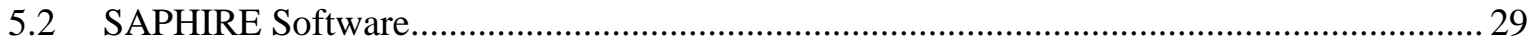

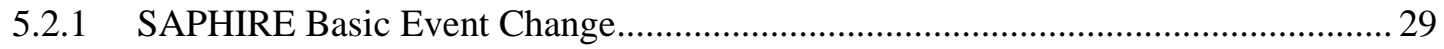

5.2.2 Partial Alpha Factor Model Parameter Estimation in SAPHIRE .............................. 29

5.2.3 Condition Assessment with Partial Alpha Factor Model ........................................ 31

5.3 Common-Cause Failure Treatment Guidelines.............................................................. 34

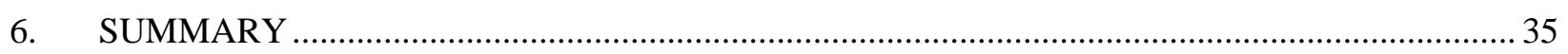

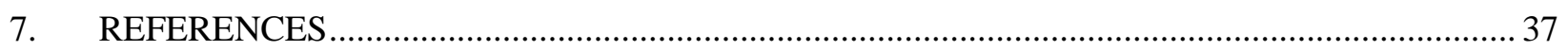

\section{FIGURES}

Figure 2-1. General dependency model basic events. 
Figure 2-2. Conceptual propagation of cause condition through coupling factor.

Figure 2-3. Conceptual construction of general dependency model. .................................................. 9

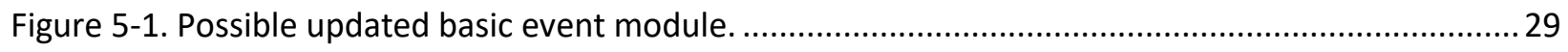

\section{TABLES}

Table 4-1. All common-cause failure events over failure causes and coupling factors in common-cause failure database.

Table 4-2. Emergency diesel generator common-cause failure events over failure causes and coupling factors in common-cause failure database.

Table 4-3. Proposal of common-cause failure database classification system from O'Connor report.

Table 4-4. Recommended common-cause failure database classification system for partial alpha factor model.

Table 4-6. Emergency diesel generator fail-to-start failure events from rads.inl.gov......

Table 4-7. All components fail-to-start failure events from rads.inl.gov. .25

Table 4-8. All components fail-to-run failure events from rads.inl.gov. 26 
Page intentionally left blank 


\section{ACRONYMS}

AFM alpha factor model

BPM basic parameter model

CAFM causal alpha factor model

CCBE common-cause basic event

CCCG common-cause component group

$\mathrm{CCF}$ common-cause failure

ECA event and condition assessment

EDG emergency diesel generator

FTR fail to run

FTS fail to start

GDM general dependency model

INL Idaho National Laboratory

NRC Nuclear Regulatory Commission

NUREG United States Nuclear Regulatory Commission Regulation

PAFM partial alpha factor model

PRA probabilistic risk assessment

SAPHIRE Systems Analysis Programs for Hands on Integrated Reliability Evaluations

SDP significance determination process

SPAR Standardized Plant Analysis Risk

U.S. United States 


\section{Feasibility Study of Developing Alternative Common- Cause Failure Model for Event Assessment}

\section{INTRODUCTION}

\subsection{Background}

The United States (U.S.) Nuclear Regulatory Commission (NRC) has developed a Standardized Plant Analysis Risk (SPAR) model for each of the operating reactors. These models have evolved over the years and are used within the U.S. NRC for many different programs. One important program is to assess events and conditions that are recognized at the different licensed reactors. To perform these assessments, conditional probabilities are calculated using the SPAR model and the identified deficiency that was observed at the licensed reactor. Certain assumptions (conditions) are input into the model prior to the assessment. Common-cause failure (CCF) adjustments are one of those inputs that require modification prior to assessing the condition. This modification can have varying degrees of impact on the final result. That is why many different approaches have been developed and implemented to include the CCF consideration in the risk modeling.

A series of U.S. NRC publications (NUREGs) have been released since the 1980s to provide guidelines for performing CCF modeling using probabilistic risk assessment (PRA) and performing CCF event data analysis. In January 1988, the U.S. NRC published NUREG/CR-4780 [1] to present the framework for including CCFs in risk and reliability evaluations. In November 1998, the U.S. NRC published NUREG/CR-5485 [2] to provide guidelines for performing CCF data analysis and modeling CCF events using PRA. In September 2007, the U.S. NRC published Revision 1 of NUREG/CR-6268 [3] to provide guidance for collecting, classifying, and coding CCF events.

Some of the more common CCF models currently in use are the beta factor model, multiple Greek letter model, and alpha factor model (AFM). While the AFM is widely utilized in PRAs, including the SPAR models, it is recognized that issues and potential improvements exist in the state of the practice CCF modeling. One such issue, as recognized in NUREG-2225 [4], is that the AFM is not causal because it does not incorporate causes of failure explicitly. While the state of practice is to use AFM for CCF analysis in event and condition assessment (ECA), the industry commented that using conditional CCF probabilities with the AFM in ECA in the guidance does not acknowledge that other causes included in the CCF probabilities do not affect the component that fails; this would bias the risk evaluation for the event or condition. The efforts to resolve the issues and develop new, alternative CCF models have been ongoing for some years.

This report is a revision of the original report, INL/LTD-14-33376. Distribution of the original report was limited to the NRC only, and the report was not made available to the public. The original report was revised as this report for public distribution. The report investigates whether two alternative CCF models could replace the AFM for use in the SPAR models for event assessment. These two alternative CCF models are the partial alpha factor model (PAFM) and general dependency model (GDM), both of which are described in the O'Connor report [5]. This report compares PAFM and GDM to identify which one should be the CCF model that replaces the AFM for use in the SPAR models for event assessment. The requirements for making this decision are availability of data, software requirements, and ease of event assessment. 
If a new alternative CCF model is selected to replace the AFM, implementation of the new model must be done with the following steps. First, new parameters must be calculated for all component groups that may be required. Second, new coding must be developed for SAPHIRE Version 8 [6] to support the selected CCF model. An analyst can use SAPHIRE 8, Windows-based software, to perform PRA for any complex system, facility, or process. An analyst can also use SAPHIRE to model a nuclear power plant's response to initiating events, quantify associated core damage frequencies, and identify important contributors to core damage (Level 1 PRA). Currently, SAPHIRE has computational capabilities for the beta factor model, multiple Greek letter model, and AFM. Any new CCF model requires additional coding. Third, the SPAR models must be updated to include the new CCF model. Each component group in the existing models must be examined to identify all of the applicable coupling factors. This information must be recorded in the model using the newly developed code capabilities. Fourth, the modeling details and applications must be captured in related documentation and reports, including NRC training materials and SAPHIRE references. Assumptions must be developed on how to apply these coupling factors, and users must be made aware of them. For example, a maintenance activity across system boundaries may or may not be modeled. The ramification of this could be tremendous.

\subsection{Purpose}

The purpose of this study is to review and compare the two alternative CCF models, PAFM and GDM, proposed in the O'Connor report [5], and to determine which model is the preferred CCF model as the SPAR models and SAPHIRE move into the future.

The review and identification of a CCF model should be driven by accident sequence precursor analyses, a significance determination process (SDP), and an ECA. To assist in this review, common terminology is defined in Appendix A.

The outcome from this review is to have a CCF model for wide use that is more transparent for performing event assessments. The current status requires the analyst to make judgments on component failures. The new methodology would be more transparent in setting up the assessment because the CCF causes and coupling factors are modeled as part of the CCF model, eliminating some (though not all) of the issues on whether the component failure was independent or dependent. Also, these CCF causes and coupling factors have direct ties to each component within a common-cause component group (CCCG) and are data-driven via Bayesian updating.

The chosen alternative CCF model must be formatted so the SAPHIRE, Version 8, software can internally calculate dependent probability and evaluate conditional probability. This report describes how SAPHIRE can be modified to implement the alternative CCF model, and how the alternative model can be used in various situations for event assessments. 


\section{REVIEW OF COMMON-CAUSE FAILURE MODELS}

Sections 2.1 and 2.2 provide an overview of the existing CCF models that are used in SPAR models when incorporating a common-cause basic event (CCBE). Sections 2.3 and 2.4 provide an overview of the two alternative CCF models, PAFM and GDM, that could potentially be used in the SPAR models, respectively.

\subsection{Basic Parameter Model}

The basic parameter model (BPM) is the underlying model that both the PAFM and AFM use. The BPM is based on the Boolean algebra equation that is used by software codes to evaluate fault tree logic models. The BPM was proposed by Fleming, et al. [7] in 1986 and calculates the CCF basic event directly from the data.

The parameters for the common-cause events are established by:

$$
\begin{aligned}
& Q_{k}^{(m)}=\text { basic event failure frequency/probability for k components failing within a CCCG of size } \\
& \quad m,(1 \leq k \leq m) .
\end{aligned}
$$

This model is based on symmetry of the system when calculating the probabilities for each of the components within the CCCG. The following provides an example of the BPM for a three-component system where all of the components are similar (e.g., pumps).

For this simple three-component system, the notations are as follows:

$$
\begin{aligned}
& A_{I}=B_{I}=C_{I}=\text { independent failure of component } A \text {, } B \text {, or } C \\
& C_{A B}=C_{A C}=C_{B C}=C C F \text { of components }(A \text { and } B) \text {, or }(A \text { and } C) \text { or }(B \text { and } C) \\
& C_{A B C}=C C F \text { of components }(A \text { and } B \text { and } C) .
\end{aligned}
$$

The failures listed above are now grouped into the total failure of each component as:

$$
\begin{aligned}
& \mathrm{A}_{\mathrm{T}}=\mathrm{A}_{\mathrm{I}} \cup \mathrm{C}_{\mathrm{AB}} \cup \mathrm{C}_{\mathrm{AC}} \cup \mathrm{C}_{\mathrm{ABC}} \\
& \mathrm{B}_{\mathrm{T}}=\mathrm{B}_{\mathrm{I}} \cup \mathrm{C}_{\mathrm{AB}} \cup \mathrm{C}_{\mathrm{BC}} \cup \mathrm{C}_{\mathrm{ABC}} \\
& \mathrm{C}_{\mathrm{T}}=\mathrm{C}_{\mathrm{I}} \cup \mathrm{C}_{\mathrm{AC}} \cup \mathrm{C}_{\mathrm{BC}} \cup \mathrm{C}_{\mathrm{ABC}} .
\end{aligned}
$$

To equate the total failure for each component into the proper Q-terms:

$$
\begin{aligned}
& \mathrm{Q}_{1}=\mathrm{P}\left[\mathrm{A}_{\mathrm{I}}\right]=\mathrm{P}\left[\mathrm{B}_{\mathrm{I}}\right]=\mathrm{P}\left[\mathrm{C}_{\mathrm{I}}\right] \\
& \mathrm{Q}_{2}=\mathrm{P}\left[\mathrm{C}_{\mathrm{AB}}\right]=\mathrm{P}\left[\mathrm{C}_{\mathrm{AC}}\right]=\mathrm{P}\left[\mathrm{C}_{\mathrm{BC}}\right] \\
& \mathrm{Q}_{3}=\mathrm{P}\left[\mathrm{C}_{\mathrm{ABC}}\right] .
\end{aligned}
$$

To generate the Boolean equation based on the three-train system, the resultant equation is:

$$
\mathrm{Q}_{\mathrm{T}}=\mathrm{Q}_{1}+2 \mathrm{Q}_{2}+\mathrm{Q}_{3}
$$

To estimate the Q-terms, the equation is:

$$
Q_{k}^{m}=\frac{n_{k}}{N_{k}}
$$

where

$$
\begin{aligned}
& n_{k}=\begin{array}{l}
\text { number of failure events that resulted in } k \text { components failing within a CCCG of size } m,(1 \leq \\
k \leq m)
\end{array} \\
& N_{k}=\text { number of demands on any } k \text { component in the common-cause group. }
\end{aligned}
$$


To estimate $Q_{k}^{m}$, the number of $n_{k}$ events must be counted that involve $k$ failures in $N_{k}$ demands (or $N_{T}$ total time for failure rate) for all of the $k$ components within the CCF group. To estimate $N_{k}$, the following equation is used based on the assumption that if each time the system is demanded all of the $k$ components receive the demand:

$$
N_{k}=\left(\begin{array}{c}
m \\
k
\end{array}\right) N_{D}
$$

Based on the testing scheme and estimated $N_{k}$, the following equations are used to determine the Q-terms [2]:

$$
\begin{gathered}
Q_{k}^{m}=\frac{n_{k}}{\left(\begin{array}{c}
m \\
k
\end{array}\right) N_{D}} \text { non-staggered testing } \\
Q_{k}^{m}=\frac{n_{k}}{m\left(\begin{array}{c}
m \\
k
\end{array}\right) N_{D}} \text { staggered testing }
\end{gathered}
$$

where

$N_{D}=$ number of demands on the system (or time $\mathrm{T}$ ).

The total component failure rate is calculated as:

$$
Q_{t}=\sum_{k=1}^{m}\left(\begin{array}{c}
m-1 \\
k-1
\end{array}\right) Q_{k}^{m}
$$

\subsection{Alpha Factor Model}

The AFM is used in the SPAR models to calculate the CCF event probabilities for redundant components within a system. The AFM is a ratio-type model used to calculate the different Q-term parameters from the BPM discussed in Subsection 2.1.

Each $\alpha_{k}$ factor is the probability that, given a failure, it will fail $k$ components out of $m$ components within the CCCG. The AFM parameters are defined and calculated as discussed in NUREG/CR-5485 [2] using the following maximum likelihood estimators:

$$
\hat{\alpha}_{k}=\frac{n_{k}}{\sum_{k=1}^{m} n_{k}}
$$

where

$\mathrm{m}=$ number of redundant components

$n_{k}=$ number of failure events that resulted in $\mathrm{k}$ components failing within a CCCG of size $\mathrm{m},(1 \leq$ $\mathrm{k} \leq \mathrm{m})$

$\alpha_{k}=$ fraction of total failure events that occur in the system resulting in $\mathrm{k}$ out of $\mathrm{m}$ failures.

The AFM is then used to estimate the basic event probabilities representing CCF events for redundant components within a system using the following equation, as applicable [2]:

$$
\begin{gathered}
Q_{k}^{(m)}=k\left(\begin{array}{c}
m-1 \\
k-1
\end{array}\right)^{-1} \cdot \frac{\alpha_{k}}{\alpha_{t}} \cdot Q_{t} \text { non-staggered test data } \\
Q_{k}^{(m)}=\left(\begin{array}{c}
m-1 \\
k-1
\end{array}\right)^{-1} \cdot \alpha_{k} \cdot Q_{t} \text { staggered test data }
\end{gathered}
$$

where 
$\left(\begin{array}{c}m-1 \\ k-1\end{array}\right)=\frac{(m-1) !}{(k-1) !(m-k) !}$ and $\alpha_{t}=\sum_{i=1}^{m} k \alpha_{k}$

$Q_{k}^{(m)}=$ basic event failure frequency/probability for $k$ components failing within a CCCG of size $m$, $(1 \leq k \leq m)$

$Q_{t}=$ total failure frequency/probability of each component due to independent and common-cause events.

The alpha parameters are ratios based on the failure of $k$ components out of $m$ components; therefore, $\alpha 1+\alpha 2+\alpha 3+\ldots \alpha m=1.0$.

\subsection{Partial Alpha Factor Model}

The PAFM can be viewed as a subset of the AFM. The AFM starts with the same premise of determining the failure of $k$ components out of $m$ components within a CCCG. The difference, which is discussed below and in later sections, is breaking the alpha parameters into coupling factors as used in O'Connor report [5]. The idea behind breaking the alpha factors into coupling factors is to provide additional insights and help when performing event assessments. The following information was obtained from a study performed to identify new models to evaluate CCF probabilities and presented here use these new models in event assessment [5].

The PAFM starts with the same parametric estimate as the AFM, which is based on the BPM. The starting equation shown below is for a staggered testing scheme (the non-staggered test data equation is similar and shown in Subsection 2.2) to calculate the individual Q-terms for a CCCG of size, $m$ :

$$
Q_{k}^{(m)}=\left(\begin{array}{c}
m-1 \\
k-1
\end{array}\right)^{-1} \cdot \alpha^{\prime}{ }_{k} \cdot Q_{t} \text { staggered test data }
$$

The PAFM calculates a different alpha parameter (or partial alpha factor) for each identified coupling factor. For example, if three different coupling factors have been identified as leading to failure of multiple redundant components, then the alpha parameter that is used in the above equation, $\alpha^{\prime}{ }_{k}$, is based on each of these coupling factors. Three partial alpha parameters are calculated using the obtained data. This model then applies a weighting factor, $\gamma$, to each partial alpha parameter. This weighting factor (or gamma factor) represents the portion of system failures which have the potential to propagate through the coupling factor. For example, $\gamma_{i}$ is the portion of failures that have the potential to propagate through coupling factor $i$.

The alpha term in Equation 10 is determined as:

$$
\alpha_{k}^{\prime}=\sum_{i \in r} \gamma_{i} \alpha_{k, i}
$$

where

$$
\begin{aligned}
& \alpha_{k}^{\prime}=\text { assessed alpha factor (this is the system alpha factor that only considers the causes shared by } \\
& \text { the components within the CCCG where } 2 \leq k \leq m \text { ). } \\
& r=\text { coupling factor shared by the components within the CCCG being analyzed, } r \in\{1,2,3, \ldots, w\} \\
& \alpha_{k, i}=\text { partial alpha factor that represents the portion of system failure events that resulted in } k \\
& \text { components failing within a CCCG of size } m(1 \leq k \leq m) \text { when there was a potential for } \\
& \text { failure propagation through coupling factor } i \text { where } i \in\{1,2,3, \ldots, w\} \\
& \gamma_{i}=\text { portion of failure events that had the potential to propagate through coupling factor } i \text { where } i \\
& \in\{1,2,3, \ldots, w\}
\end{aligned}
$$


$\alpha^{\prime}{ }_{1}$ is the single failures and any contribution from coupling factors that are not shared.

$$
\alpha^{\prime}{ }_{1}=1-\sum_{k=2}^{m} \alpha_{k}^{\prime}
$$

The maximum likelihood estimate for the partial alpha factor in Equation 11 is:

$$
\hat{\alpha}_{k, i}=\frac{n_{k, i}}{n_{p, i}}
$$

where

$$
\begin{aligned}
n_{k, i}= & \text { number of failure events that resulted in } k \text { components failing within a CCCG of size } m,(1 \leq \\
& k \leq m) \text { of coupling factor } i \text { where } i \in\{1,2,3, \ldots, w\} \\
n_{p, i}= & \text { total number of failure events that had the opportunity for the failure to propagate through } \\
& \text { coupling factor } i \text { where } i \in\{1,2,3, \ldots, w\} .
\end{aligned}
$$

When the failure cause taxonomy is defined so that each cause could only propagate through one coupling factor, the estimate becomes:

$$
\hat{\alpha}_{k, i}=\frac{n_{k, i}}{n_{t, i}}
$$

where

$n_{t, i}=\sum_{k=1}^{m} n_{k, i}$, total number of failure events for coupling factor/cause $i$ where $i \in\{1,2,3, \ldots, w\}$

The maximum likelihood estimate for the gamma factor in Equation 11 is:

$$
\hat{\gamma}_{i}=\frac{n_{p, i}}{n_{t}}
$$

where

$n_{t}=$ total number of failure events

When the failure cause taxonomy is defined so that each cause could only propagate through one coupling factor, the estimate becomes:

$$
\hat{\gamma}_{i}=\frac{n_{t, i}}{n_{t}}
$$

and

$$
\sum_{i=1}^{w} \hat{\gamma}_{i}=1
$$

\subsection{General Dependency Model}

The GDM is another CCF model that was researched to handle dependent-type failures [5]. GDM uses causes as the means of evaluating the parameters that define the overall failure probability of a component. This CCF model is developed using Bayesian Network nodes to link the causes together between the different components. By using the Bayesian Network, the assessment becomes a conditional probability calculation to obtain the overall component and system probability.

The GDM defines the component failure probability/rate, $Q_{t}$ (using the same nomenclature as all CCF models), as the combination of component failure probabilities for each failure cause. Each failure cause is independent of the others; therefore, the assessment of $Q_{t}$ is the summation of the failure probability for each cause. The difference between GDM and the other models is the causes that lead to the total failure of the components. In the AFM and PAFM, symmetry is assumed; therefore, each component has the same failure probability, $Q_{t}$. For the GDM, the $Q_{t}$ can be different for each component 
due to the potential failure causes that can be expanded through the Bayesian Network. The following equation illustrates how to calculate the total failure probability of Component A, given the potential different failure causes:

$$
P(A)=Q_{t}=\sum_{i=1}^{w} Q_{t, i}
$$

where

$A=$ random variable for the failure of Component $\mathrm{A}$

$Q_{t}=$ total failure probability for a component

$Q_{t, i}=$ failure probability of a component due to cause $i$.

The probability of the component failure due to a specific cause is determined by two parameters. The first is the probability that the component fails when it is tested by a specific cause, $p_{i}$. The second is the conditional probability of the cause. Therefore, the probability of component failure due to cause $i$ is:

$$
Q_{t, i}=p_{i} Q_{E, i}
$$

where

$$
\begin{aligned}
& p_{i}=\text { probability a component fails when tested by cause } i \\
& Q_{E, i}=\text { cause condition probability of cause } i
\end{aligned}
$$

The overall failure probability of Component A becomes the union of each failure cause. This probability calculation is performed using the following rare event approximation or the minimal cut set upper bound equation:

$$
\begin{gathered}
P(A)=\sum_{i=1}^{w} p_{i} Q_{E, i}(\text { rare event approximation }) \\
P(A)=1-\prod_{i=1}^{w}\left(1-Q_{t, i}\right)(\text { minimal cut set upper bound approximation }) \\
=1-\prod_{i=1}^{w}\left(1-p_{i} Q_{E, i}\right)
\end{gathered}
$$

The concept of the GDM on how an individual component is represented and the probability is calculated is shown in Figure 2-1, which is the starting point for the GDM.

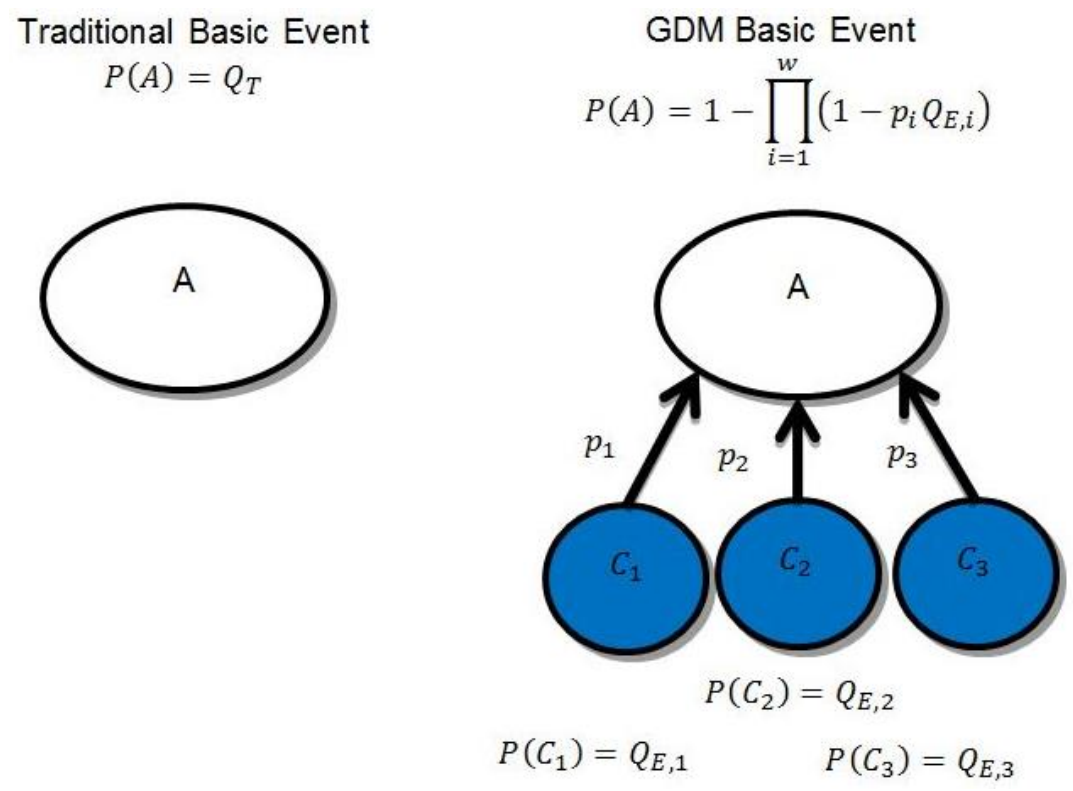

Figure 2-1. General dependency model basic events [5]. 
The GDM can evaluate the strength of the cause condition between redundant components, such as emergency diesel generators (EDGs). This cause can be evaluated probabilistically using a coupling strength factor, $\eta_{i}$. Figure 2-2 shows conceptually how the GDM can account for high fragility and low coupling factor strength through the use of local cause condition nodes.
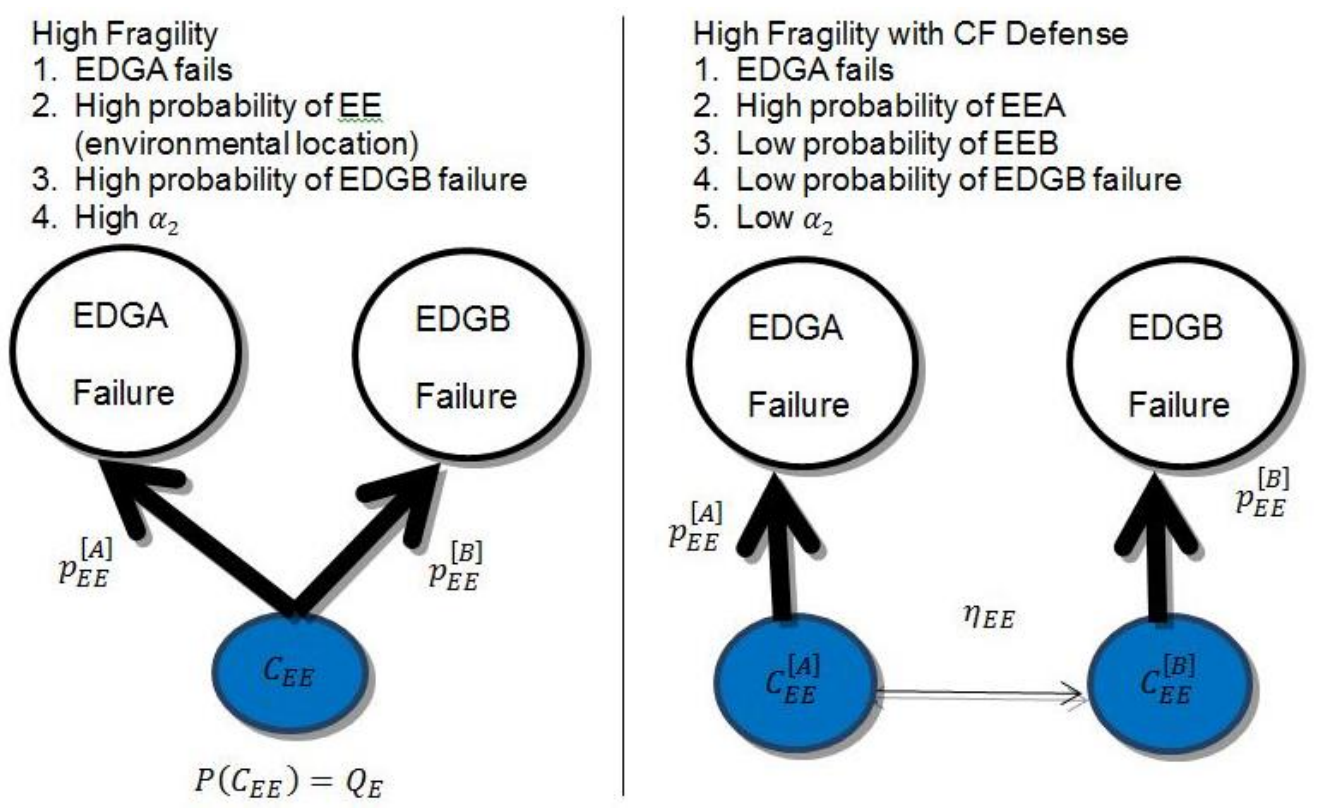

Figure 2-2. Conceptual propagation of cause condition through coupling factor [5].

Because the coupling factor strength, $\eta_{i}$, is probabilistic, it ranges between 0 and 1 , where:

- $\eta_{i}=0$. When the coupling factor strength is zero, there is no chance that the local cause condition at one component can propagate to the second component. However the second component may still fail from an independent occurrence of that cause condition.

- $\eta_{i}=1$. A cause condition at either component means that the same cause condition is present at the other component.

To model these limits, the cause condition probability, $Q_{E, i}$ is split into independent $\left(Q_{I E, i}\right)$ and common-cause error $\left(Q_{C E, i}\right)$ probabilities. This is similar to the BPM discussed above; however, it is defined for each cause condition versus all causes rolled as a single input. The failure probability of a component for each cause condition is determined using the following equations for both the independent part and common-cause part:

$$
\begin{gathered}
P\left(X_{i}\right)=Q_{C E, i}=\eta_{i} Q_{E, i} \\
P\left(I_{i}\right)=Q_{I E, i}=\left(1-\eta_{i}\right) Q_{E, i}
\end{gathered}
$$

where

$X_{i}=$ random variable for the common-cause condition for cause $i$

$I_{i}=$ random variable for the independent-cause condition for cause $i$

$\eta_{i}=$ coupling factor strength for cause $i$.

To obtain the total probability of the cause condition, $Q_{E, E E}$, the independent- and common-cause conditions are added together because they are mutually exclusive events. Therefore, the local cause condition probability is calculated using the following equation: 


$$
Q_{E, E E}=Q_{I E, E E}+Q_{C E, E E}
$$

where

$Q_{E, E E}=$ total probability of cause condition, EE (environmental location)

$Q_{I E, E E}=$ independent-cause condition probability of cause $\mathrm{EE}$

$Q_{C E, E E}=$ common-cause condition probability of cause EE.

Figure 2-3 shows the construction of the GDM with consideration for a coupling factor strength parameter.

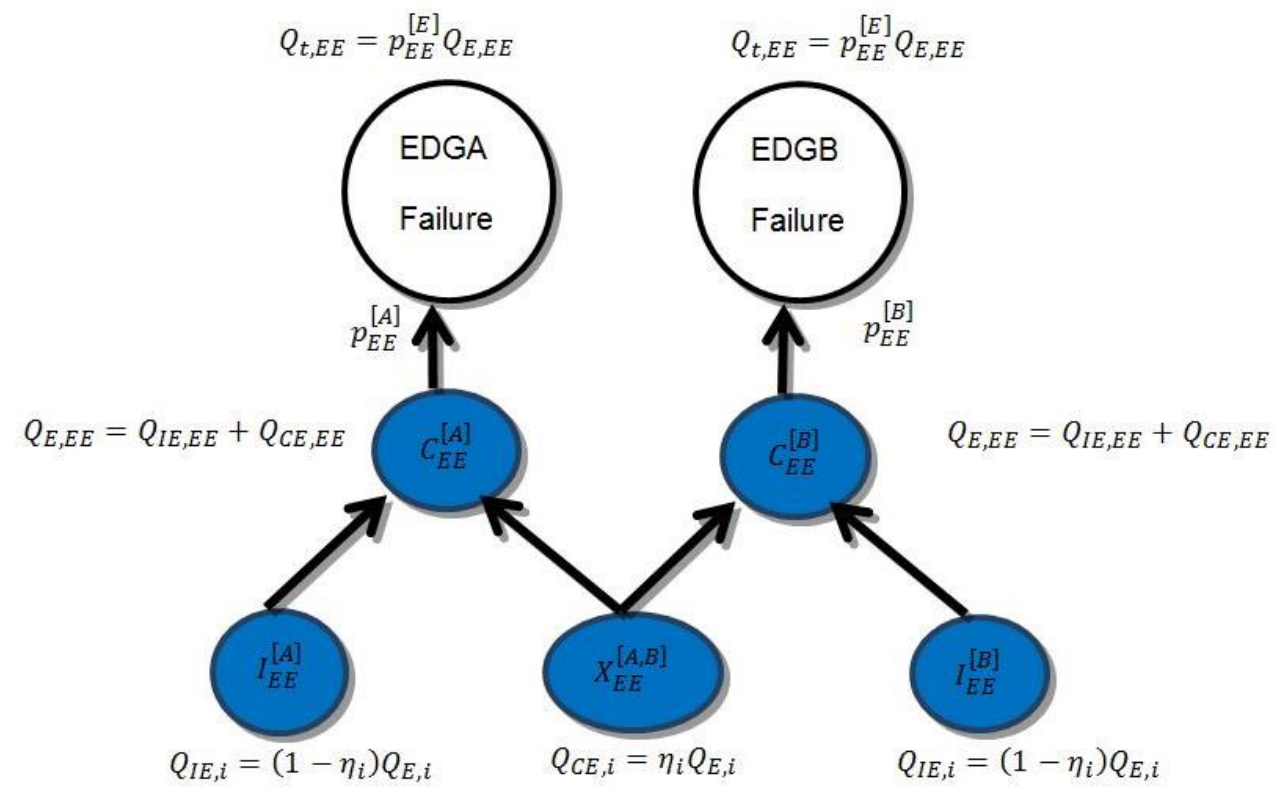

Figure 2-3. Conceptual construction of general dependency model [5].

Based on the equations above for the GDM, the following provides a definition for each of the parameters:

- Fragility, $p_{i}$. The probability that a component will fail given that a cause condition is evident for cause $i$. It is a measure of the component's ability to resist failure. The component's fragility is affected by such things as the component's design, materials, and compliance to reliability durability standards.

- Cause condition probability, $Q_{E, i}$. The probability that the cause condition for cause $i$ is present during a mission period. It represents the frequency and strength of failure causes. It can be a function of features such as quality assurance, process maturity, and human performance. The term recognizes that a cause condition may exist for extended periods of time or multiple mission periods, e.g., for a PRA mission time of 24 hours, a cause condition may exist for 100 days, or 100 mission periods.

- Coupling factor strength, $\eta_{i}$. The probability that, if a cause condition exists at a component, it will propagate to other components. It is a measure of defenses against coupling factors and of the repeatable nature of the cause condition.

- To estimate each of the parameters, the following provides the maximum likelihood estimations. To actually perform this step, a Bayesian analysis is performed to obtain uncertainty parameters. 
- For each cause, the Bayesian Network is fully specified once the three parameters $p_{i}, Q_{E, i}$, and $\eta_{i}$ are known. However, using data from the U.S. NRC failure databases, the observable quantities are:

- The failure rate for a component due to cause $i, Q_{t, i}$.

- The propensity for CCF due to cause $i$ in a perfectly symmetrical CCCG, $\alpha_{2, i}$.

The failure probability for cause $i, Q_{t, i}$, is an observable metric that can assist in the calculation of the GDM parameters through the relationship:

$$
Q_{t, i}=p_{i} Q_{E, i}
$$

The maximum likelihood estimation for the failure probability of a component due to cause $i, Q_{t, i}$ is:

$$
\hat{Q}_{t, i}=\frac{n_{F, i}}{N_{1}}
$$

where

$n_{F, i}=$ total number of failures due to cause $i$

$N_{1}=$ total number of demands on a single component.

The quantities $n_{F, i}$ and $N_{1}$ are component event data, as opposed to CCF event data. To help illustrate this, assume a two-component redundancy where both components are demanded when the system is demanded. Component 1 fails in the first demand, Component 2 fails in the second demand, and neither component fails in the third demand. This makes three demands on each component, giving a total of six component demands for the system with two failures. The maximum likelihood estimation of failure probability will be:

$$
2 / 6=1 / 3
$$

The fragility parameter, $p_{i}$, may be directly estimated from data by letting $n_{E, i}$ be the number of mission periods for which the cause condition existed and $n_{F, i}$ be the number of failures due to the cause condition $i$. The fragility is then estimated using the following equation:

$$
\widehat{p_{l}}=\frac{n_{F, i}}{n_{E, i}}
$$

where

$n_{F, i}=$ total number of failures due to cause $i$

$n_{E, i}=$ number of mission periods for which cause condition $i$ existed.

The cause condition probability, $Q_{E, i}$, may be directly estimated from data by letting $n_{E, i}$ be the number of mission periods for which the cause condition $i$ existed and $n_{m}$ be the number of missions over the period of data collection. The error rate is then estimated using the following equation:

$$
\hat{Q}_{E, i}=\frac{n_{E, i}}{n_{m}}
$$

where

$$
\begin{aligned}
& n_{E, i}=\text { number of mission periods for which cause condition } i \text { existed } \\
& n_{m}=\text { total number of mission periods. }
\end{aligned}
$$

The coupling factor strength, $\eta_{i}$, may be directly estimated from data by letting $n_{I E, i}$ be the number of mission periods for which the cause condition $i$ existed locally at a component, without occurring at other components, and letting $n_{C E, i}$ be the number of mission periods for which the cause condition $i$ existed at multiple components. The coupling factor strength is then estimated using the following equation: 


$$
\hat{\eta}_{i}=\frac{n_{E, i}}{n_{m}}
$$

where

$$
\begin{aligned}
& n_{E, i}=\text { number of mission periods for which cause condition } i \text { existed } \\
& n_{m}=\text { total number of mission periods. }
\end{aligned}
$$




\section{FEASIBILITY OF ALTERNATE COMMON-CAUSE FAILURE MODELS}

The feasibility of using one of the two alternative CCF models instead of the current state-of-the-practice AFM is discussed in this section. This section discusses the strengths and limitations of each alternative CCF model (PAFM and GDM) in comparison to each other and the AFM. Part of the feasibility study was to determine if the SPAR models should be updated with one of these alternative CCF models.

\subsection{Strengths of Alternative Common-Cause Failure Models}

\subsubsection{Partial Alpha Factor Model}

\subsubsection{Starting Point of Partial Alpha Factor Model}

The PAFM starts with the established AFM and expands it to explicitly represent the causes of CCFs. This representation of causes aids in SDP analyses and ECAs as long as inspector-identified failure or deficiency aligns with the CCF cause modeled in the PAFM. In this case, the analyst can select that specific cause, and the proper CCF adjustment will be performed automatically. This can eliminate some guesswork on whether the failure was an independent or a dependent failure. The CCF adjustment is automatic and specific to the failure, versus the CCF adjustment that uses the population-data-based AFM parameters. This refinement can speed up analyses and also provide discussion points on how the failure cause is modeled. Using the PAFM in ECA might address the noncausal CCF model issue as well as the associated comment from the industry on the report regarding the using of the conditional $\mathrm{CCF}$ probabilities with the AFM in ECA.

\subsubsection{Weighting Alpha Parameters}

The weighting of the alpha parameters via the gamma parameter can help in expanding out the different failures that have been identified from the data. This identification helps in alpha parameter calculations versus the current population collection for the alpha parameters.

\subsubsection{Component can be Part of Multiple Common-Cause Component Groups}

The ability to model a component in different CCCGs can provide a new level of detail to PRA that has not been captured. This potential coupling could provide analysts with more information about the different failure causes and their ramifications to the overall risk when the failure cause is extrapolated through PRA.

\subsubsection{General Dependency Model}

\subsubsection{Starting Point of General Dependency Model}

The GDM uses the Bayesian Network to identify and model all of the potential shared causes between components. These components can be part of a redundant group or other components that can share the same potential cause. This modeling allows for propagation of conditional probabilities to obtain the overall system failure probability (or frequency). This approach allows for the propagation of evidence through the model to obtain a new probability. Using the GDM in ECA might address the noncausal CCF model issue as well as the associated comment from the industry on the report regarding the using of the conditional CCF probabilities with the AFM in ECA. 


\subsubsection{Asymmetrical Components}

The Bayesian Network can account for asymmetrical components and probabilities. The model is expanded out to handle all input parameters independently and then the model structure when evaluated calculates the overall system probability based on the input parameters. Therefore, causes that can impact different components within the system or outside the system can be modeled and evaluated. The causes can be modeled across components since they are conditional probabilities that are data calculated or the use of Bayesian inference.

\subsection{Limitations of Alternative Common-Cause Failure Models}

\subsubsection{Partial Alpha Factor Model}

\subsubsection{Data Analysis of Partial Alpha Factor Model}

Data is the driving factor no matter which CCF model is selected. However, this approach becomes even more difficult by trying to parse up what little CCF data are available. There may be sufficient failure data; however, taking that data and parsing it up into CCF bins can be difficult. Therefore, this approach could have a lot of zero CCF events, which would then rely on prior information as the driver to the partial alpha factor value and gamma parameter. One way to lessen the impact is to ensure the assessed alpha factor is bounded by the alpha factor that is calculated for the AFM.

As part of the data issue, the O'Connor report [5] discusses the use of weighting factors based on engineering assessment of the strength between components. This additional weighting factor used in posterior distribution determination on top of using a prior distribution with little knowledge can have a large impact on the uncertainty of the partial alpha factors, therefore, compounding the uncertainty in the estimate of these partial alpha factor parameters.

\subsubsection{Asymmetrical Failure Probabilities}

The PAFM does not handle asymmetrical failure probabilities. This is the same issue with the AFM. These models are based on the BPM, which assumes symmetry between the redundant components and therefore, the components must have the same probability of failure.

\subsubsection{General Dependency Model}

\subsubsection{Data Analysis of General Dependency Model}

The ability to derive the correct parameter values from the data for the GDM can be very difficult. Some model parameters may not be available from the data and therefore, rely on prior knowledge. These parameters could drive the result. Along the same path, some of the parameters may not be observable and therefore, cannot be calculated. The conditional probabilities and fragility determination for this model could be tough to evaluate.

\subsubsection{Model Complexity}

The GDM requires the development of an external software tool that uses the Bayesian Network to model the component and system failure causes and calculate all the conditional probabilities. Each cause factor has some conditional probability of leading to component failure, which in turn propagates to the top for overall system failure. The O'Connor report [5] provides background information on the use of Bayesian Network modeling to handle potential causes that can lead to system failure for a simple system. The modeling of a very complex operation with all of the potential inter-relationships would be difficult and unwieldy.

\subsubsection{Integration of Bayesian Network Software into SAPHIRE}

Solution of the Bayesian Network is not trivial, and developing a new solver as part of the SAPHIRE code base will be prohibitively expensive. In order to use the GDM, off-the-shelf software must be 
integrated into SAPHIRE or the model itself must be coded into SAPHIRE. The integration, or development of a new solver, would require the ability to input the conditional probabilities and then calculate component and CCF probabilities and be able to pass this information to the basic events modeled in PRA. This process would have to keep track of the different conditional probability pieces of the model for later use in event assessments. Then given some event, this condition must be evaluated using the built-in software to calculate the new CCF and component probability and pass this information back to the PRA model for analysis.

\subsection{Common-Cause Failure Model Selected}

Based on the review of the information provided in the O'Connor report [5], the PAFM is the best choice as an alternate CCF model to replace the current AFM for use in the SPAR models. The PAFM contains more detail than the AFM, which could make event assessments more straightforward. Using the PAFM in ECA might address the noncausal CCF model issue as well as the associated comment from the industry on the report regarding the using of the conditional CCF probabilities with the AFM in ECA. The partial alpha factors relate to causes that are expected to align well with those most often seen in event assessment. The analyst must identify the cause of a component failure, which will set the specific gamma parameter to 1.0 and all others to zero. Then, the resulting conditional probability of CCF potential is conditional on the occurrence of the identified cause.

This CCF modeling for event assessment could then reduce some of the conservatisms built into the AFM. The current AFM treats all causes as the same, when the reality is the conditional probabilities associated with different causes differ significantly.

The PAFM would be easier to incorporate into SAPHIRE because most of the structure is in place from the AFM. This CCF model is also easier to incorporate into the SPAR models because the basic events are already modeled, and only data changes into the basic events are required once the software has been updated. Therefore, no fault tree logic structure changes are necessary.

Modification of the coupling factors may also be required during analysis because the SPAR modelers will likely assume that all coupling factors exist for all component groups. An analysis will likely incorporate information not available to the SPAR modeling team; therefore, it is anticipated coupling factors will have to be verified and likely modified when the analysis is done.

The GDM has some advantages over the PAFM based on its underlying structure and the ability to update conditional and system probabilities based on new evidence. Using the GDM in ECA might address the same noncausal CCF model issue and associated industry comment as the PAFM. The GDM structure using the Bayesian Network lends itself directly to event assessment because all potential conditions are modeled explicitly. Therefore, when events occur, they can be directly modeled into the structure and the overall probability, calculated based on this new set of evidence. However, the complexity on software development, data collection, and implementation into fault tree logic models prohibits the practical use of the GDM in SPAR models. 


\section{DATA REVIEW FOR PARTIAL ALPHA FACTOR MODEL}

One key factor in determining whether the PAFM is practical to implement in SAPHIRE for event assessment using the SPAR models is to evaluate whether the current CCF database classification system and existing CCF data could support the alternative model. The proposed cause-based CCF model requires classification of failure events with a clear relationship between the failure cause and coupling factor. It assumes that each component within the CCCG for the CCF failure in the database has the potential for propagation of that cause through a coupling factor. This requirement and assumption are achieved if a mutually exclusive, one-to-one relationship exists between the failure cause and coupling factor. If the current CCF database has no such correlation between a failure cause and coupling factor, an alternate classification system must be proposed to replace the existing one. Also, data are the driving factor for any CCF model. With little CCF data available, it becomes more difficult because this limited data set must be parsed up over numerous failure causes. Many of the failure causes will have no observed CCF event; therefore, the estimate of the related partial alpha factor and gamma factor parameters of the PAFM must rely heavily on prior knowledge. Reducing the number of failure causes by grouping individual causes together into a more manageable size could mitigate the impact and ensure sufficient information is available to estimate the PAFM parameters.

Subsection 4.1 addresses the current CCF database classification system and recommends using failure cause groups for the PAFM. Subsection 4.2 assesses whether the CCF database has sufficient CCF data over different components and failure modes to estimate the partial alpha factors and gamma factors for the PAFM. Subsection 4.3 provides a review of generic CCF data for fail-to-start (FTS) and fail-torun (FTR) failure mechanisms as candidates for prior distribution.

\subsection{Database Classification System}

NUREG/CR-6268 [3] documents the CCF database and analysis methods that are used in the commercial nuclear power industry. It provides guidance on CCF event data collection, classification, and coding for the database. The CCF database is managed under the Structured Query Language (SQL) Server software and can be output to an Excel spreadsheet for data viewing and searching. The database can also be accessed through the U.S. NRC PRA database website https://rads.inl.gov, ${ }^{\text {a }}$ although the website has its predefined query system to search for data (note that the current CCF database may slightly differ from the NUREG on the CCF database [3], which was published in 2007).

To determine whether the current CCF database has the required correlation between failure cause and coupling factor, the CCF events in the database output spreadsheet were counted against their failure causes and coupling factors as documented in the database. Table 4-1 presents the distribution of a total of 434 CCF events (for all components and all failure modes) over 16 failure causes and 11 coupling factors.

As an example to further show how rare of CCF events would be,

Table 4-2 displays a total of 25 EDG CCF events (for all failure modes and redundancy) over the failure causes and coupling factors. Both Table 4-1 and

Table 4-2 show that there is no one-to-one relationship between failure causes and coupling factors in the current CCF database. For each failure cause, there is usually a number of coupling factors through which the cause can propagate. Conversely, for each coupling factor, there are a number of causes. Apparently, the current database classification system must be revised to meet the PAFM requirement on the correlation between the failure cause and coupling factor.

a The NRC CCF Database system includes proprietary information and is not available to the public. 
The O'Connor report [5] suggests that a suitable CCF database classification system could be similar to the one in Table 4-3 (the coding for the failure causes and coupling factors were added by this study). The suggested database classification system includes 16 failure causes/coupling factors. While having such a classification system with more failure causes for a cause-based CCF model is desirable, current CCF data may not be sufficient to support the model with the individual failure causes.

Table 4-2 shows that there is only a total of 25 EDG CCF events from the database. Three out of 16 failure causes have zero CCF events. When these EDG CCF events are further parsed for different failure modes, such as FTS and FTR, more failure causes will have no observed CCF events. To address the issue of scarce CCF events, it is suggested that cause groups be used instead of individual causes for the PAFM. The 16 individual failure causes in the current CCF database classification system remain unchanged, but are grouped into five cause groups: Component, Design, Environment, Human, and Other.

Table 4-4 shows the recommended classification system for use in the CCF database for the PAFM. The CCF Cause Group column in Table 4-4 includes the five cause groups that will be used in the PAFM for SPAR models. The Cause Code and Failure Cause columns in Table 4-4 are the same as in the current classification system. The Coupling Group and Coupling Factor columns are new to the current system and represent a direct relationship between the failure cause and coupling factor. Although the recommended cause group approach may miss some details of specific failure causes, it is still sufficient to not lose important information while, at the same time, it represents a more-manageable set that can be tracked and analyzed and be better supported by the current CCF data. The CCF database would require no or minimal change on the failure cause classification, but the coupling factors in the database would need to be reclassified.

Table 4-5 provides a comparison between the recommended CCF cause groups and the current failure causes. 
Table 4-1. All common-cause failure events over failure causes and coupling factors in common-cause failure database.

\begin{tabular}{|c|c|c|c|c|c|c|c|c|c|c|c|c|c|}
\hline \multicolumn{2}{|r|}{ Failure Cause } & \multicolumn{11}{|c|}{ Coupling Factors $^{1}$} & \multirow{2}{*}{ Total } \\
\hline Code & Description & $\mathrm{EE}$ & EI & HDCP & HDSC & HQIC & HQMM & OMTC & OMTP & OMTS & OOOP & OOOS & \\
\hline $\mathrm{DC}$ & Construction installation error or inadequacy & & & 63 & 2 & 3 & & & 3 & 3 & & & 74 \\
\hline $\mathrm{DE}$ & Design error or inadequacy & 3 & 2 & 46 & 8 & 2 & & 1 & 3 & & 1 & 1 & 67 \\
\hline $\mathrm{DM}$ & Manufacturing error or inadequacy & & & 7 & & 1 & 3 & & & 2 & & & 13 \\
\hline EA & Ambient environmental stress & 5 & 1 & & & & & 1 & & & 1 & & 8 \\
\hline $\mathrm{EC}$ & State of other component & 2 & & 4 & 16 & & & 1 & 1 & & & & 24 \\
\hline EE & Extreme environmental stress & 32 & 9 & 4 & 2 & & & 2 & & & & & 49 \\
\hline HA & Accidental human action & & & 1 & & 1 & & & 4 & 8 & & & 14 \\
\hline $\mathrm{HM}$ & Inadequate maintenance & 2 & 2 & 2 & 1 & & & 4 & 4 & 2 & & & 17 \\
\hline HP & Human action procedure & & & 2 & & & & & 4 & 3 & 1 & 1 & 11 \\
\hline IC & Internal to component; piece-part & & 4 & 18 & 4 & & 3 & 42 & 9 & & & & 80 \\
\hline IE & Internal environment & 4 & 12 & 1 & & & & & 2 & & & & 19 \\
\hline IQ & Setpoint drift & & & 1 & & & & & 1 & & & & 2 \\
\hline IW & Age or Wear & 1 & 1 & 2 & 1 & & 1 & 4 & & & & & 10 \\
\hline $\mathrm{OK}$ & Unknown & & & 1 & & & & & & & & & 1 \\
\hline OT & Other & & & 6 & 2 & & & 1 & & 1 & & & 10 \\
\hline PA & Inadequate procedure & & & 2 & & & & 1 & 23 & 7 & 2 & & 35 \\
\hline Total & & 49 & 31 & 160 & 36 & 7 & 7 & 57 & 54 & 26 & 5 & 2 & 434 \\
\hline
\end{tabular}

1 Coupling factor code descriptions: EE = External Environment, EI = Internal Environment, HDCP = Hardware Design Component, HDSC = Hardware Design System, HQIC = Hardware Quality Installation, HQMM = Hardware Quality Maintenance, OMTC = Operational Maintenance Schedule, OMTP = Operational Maintenance Procedure, OMTS = Operational Maintenance Staff, OOOP = Operational Operation Procedure, OOOS = Operational Operation Staff 
Table 4-2. Emergency diesel generator common-cause failure events over failure causes and coupling factors in common-cause failure database.

\begin{tabular}{|c|c|c|c|c|c|c|c|c|c|c|c|c|c|}
\hline \multicolumn{2}{|r|}{ Failure Cause } & \multicolumn{11}{|c|}{ Coupling Factors $^{1}$} & \multirow{2}{*}{ Total } \\
\hline Code & Description & $\mathrm{EE}$ & EI & $\mathrm{HDCP}$ & HDSC & HQIC & HQMM & OMTC & OMTP & OMTS & OOOP & OOOS & \\
\hline DC & Construction installation error or inadequacy & & & & 2 & & & & & & & & 2 \\
\hline DM & Manufacturing error or inadequacy & & & 2 & & & & & & & & & 2 \\
\hline EA & Ambient environmental stress & & & & & & & & & & & & 0 \\
\hline $\mathrm{EE}$ & Extreme environmental stress & & 2 & & & & & & & & & & 2 \\
\hline HA & Accidental human action & & & & & & & & & 1 & & & 1 \\
\hline HM & Inadequate maintenance & & & & & & & 1 & & & & & 1 \\
\hline HP & Human action procedure & & & & & & & & 1 & & & & 1 \\
\hline IW & Age or Wear & & & 1 & & & & & & & & & 1 \\
\hline OK & Unknown & & & 1 & & & & & & & & & 1 \\
\hline OT & Other & & & & & & & & & & & & 0 \\
\hline PA & Inadequate procedure & & & & & & & & 3 & & & & 3 \\
\hline Total & & 1 & 2 & 6 & 8 & 0 & 0 & 2 & 5 & 1 & 0 & 0 & 25 \\
\hline
\end{tabular}


Table 4-3. Proposal of common-cause failure database classification system from O'Connor report.

\begin{tabular}{|c|c|c|c|}
\hline Failure Cause Code & Failure Cause Description & Coupling Factor Code & Coupling Factor Description \\
\hline IP & Installation procedural cause & IP & Same install procedure \\
\hline IT & Installation human cause & IT & Same install team \\
\hline $\mathrm{CD}$ & Component design deficiency & $\mathrm{CD}$ & Same component design \\
\hline SD & System design deficiency & SD & Same system design \\
\hline AW & Age/wear & AW & Same age within mission period \\
\hline $\mathrm{CM}$ & Component manufacturer fault & $\mathrm{CM}$ & Same component and manufacturer \\
\hline OR & Operator error & OR & Same operators \\
\hline OP & Operation procedure error & OP & Same operating procedures \\
\hline MT & Maintainer error & MT & Same maintenance team \\
\hline MP & Maintenance procedure error & MP & Same maintenance procedure \\
\hline MS & Maintenance schedule error & MS & Same maintenance schedule \\
\hline EI & Environment internal induced & EI & Same fluid \\
\hline $\mathrm{EE}$ & Environment external induced & $\mathrm{EE}$ & Same location \\
\hline
\end{tabular}


Table 4-4. Recommended common-cause failure database classification system for partial alpha factor model.

\begin{tabular}{|c|c|c|c|c|}
\hline CCF Cause Group & Cause Code & Failure Cause & Coupling Group & Coupling Factor \\
\hline \multirow{3}{*}{$\begin{array}{l}\text { Component } \\
\text { (GC) }\end{array}$} & $\mathrm{IC}$ & Internal to component, piece-part & \multirow{3}{*}{$\begin{array}{l}\text { Component } \\
\text { (GC) }\end{array}$} & \multirow[t]{3}{*}{ Same component age, internals, or setpoint } \\
\hline & IQ & Setpoint drift & & \\
\hline & IW & Age/wear & & \\
\hline \multirow[t]{3}{*}{$\begin{array}{l}\text { Design } \\
\text { (GD) }\end{array}$} & $\mathrm{DC}$ & $\begin{array}{l}\text { Construction installation error or } \\
\text { inadequacy }\end{array}$ & \multirow[t]{3}{*}{$\begin{array}{l}\text { Design } \\
\text { (GD) }\end{array}$} & \multirow[t]{3}{*}{$\begin{array}{l}\text { Same component design, manufacturer, or } \\
\text { installation team/ procedure }\end{array}$} \\
\hline & $\mathrm{DE}$ & Design error or inadequacy & & \\
\hline & $\mathrm{DM}$ & Manufacturing error or inadequacy & & \\
\hline \multirow{3}{*}{$\begin{array}{l}\text { Environment } \\
\quad(\mathrm{GE})\end{array}$} & EA & Ambient environmental stress & \multirow{3}{*}{$\begin{array}{l}\text { Environment } \\
\quad(\mathrm{GE})\end{array}$} & \multirow[t]{3}{*}{ Same location, or fluid } \\
\hline & $\mathrm{EE}$ & Extreme environmental stress & & \\
\hline & IE & Internal environment & & \\
\hline \multirow{4}{*}{$\begin{array}{l}\text { Human } \\
(\mathrm{GH})\end{array}$} & HA & Accidental human action & \multirow{4}{*}{$\begin{array}{c}\text { Human } \\
(\mathrm{GH})\end{array}$} & \multirow{4}{*}{$\begin{array}{l}\text { Same operational/maintenance team/procedure, or } \\
\text { maintenance schedule }\end{array}$} \\
\hline & $\mathrm{HM}$ & Inadequate maintenance & & \\
\hline & HP & Human action procedure & & \\
\hline & $\mathrm{PA}$ & Inadequate procedure & & \\
\hline \multirow{3}{*}{$\begin{array}{l}\text { Other } \\
(\mathrm{GO})\end{array}$} & $\mathrm{EC}$ & State of other component & \multirow{3}{*}{$\begin{array}{l}\text { Other } \\
(\mathrm{GO})\end{array}$} & \multirow[t]{3}{*}{ Other or unknown } \\
\hline & OT & Other & & \\
\hline & $\mathrm{OK}$ & Unknown & & \\
\hline
\end{tabular}


Table 4-5. Recommended common-cause failure cause groups versus current failure causes.

\begin{tabular}{|c|c|c|c|}
\hline CCF Cause Group & Current Cause Code & Failure Cause Description & Failure Cause Meaning \\
\hline \multirow[t]{3}{*}{ Component } & IC & Internal to component, piece-part & $\begin{array}{l}\text { Used when the cause of a failure is a non-specific result of a failure } \\
\text { internal to the component that failed other than aging or wear. }\end{array}$ \\
\hline & IQ & Setpoint drift & $\begin{array}{l}\text { Used when the cause of a failure is the result of setpoint drift or } \\
\text { adjustment. }\end{array}$ \\
\hline & IW & Age/wear & $\begin{array}{l}\text { Used when the cause of a failure is a non-specific aging or wear } \\
\text { issue. }\end{array}$ \\
\hline \multirow[t]{3}{*}{ Design } & DC & Construction installation error or inadequacy & $\begin{array}{l}\text { Used when a construction or installation error is made during the } \\
\text { original or modification installation. This includes specification of } \\
\text { incorrect component or material. }\end{array}$ \\
\hline & DE & Design error or inadequacy & Used when a design error is made. \\
\hline & $\mathrm{DM}$ & Manufacturing error or inadequacy & $\begin{array}{l}\text { Used when a manufacturing error is made during component } \\
\text { manufacture. }\end{array}$ \\
\hline \multirow[t]{3}{*}{ Environment } & EA & Ambient environmental stress & $\begin{array}{l}\text { Used when the cause of a failure is the result of an environmental } \\
\text { condition from the location of the component. }\end{array}$ \\
\hline & $\mathrm{EE}$ & Extreme environmental stress & $\begin{array}{l}\text { Used when the cause of a failure is the result of an environmental } \\
\text { condition that places a higher than expected load on the equipment } \\
\text { and is transitory in nature. }\end{array}$ \\
\hline & IE & Internal environment & $\begin{array}{l}\text { Internal environment led to the failure. Debris/foreign material as } \\
\text { well as an operating medium chemistry issue. }\end{array}$ \\
\hline \multirow[t]{3}{*}{ Human } & HA & Accidental human action & $\begin{array}{l}\text { Used when a human error (during the performance of an activity) } \\
\text { results in an unintentional or undesired action. }\end{array}$ \\
\hline & HM & Inadequate maintenance & $\begin{array}{l}\text { Used when a human error (during the performance of maintenance) } \\
\text { results in an unintentional or undesired action. }\end{array}$ \\
\hline & $\mathrm{HP}$ & Human action procedure & $\begin{array}{l}\text { Used when the procedure is not followed or the procedure is } \\
\text { incorrect. For example, when a missed step or incorrect step in a } \\
\text { surveillance procedure results in a component failure. }\end{array}$ \\
\hline
\end{tabular}




\begin{tabular}{|c|c|l|l|}
\hline CCF Cause Group & Current Cause Code & Failure Cause Description & Failure Cause Meaning \\
\hline \multirow{2}{*}{ Other } & PA & Inadequate procedure & $\begin{array}{l}\text { Used when the cause of a failure is the result of an inadequate } \\
\text { operating or maintenance procedure. }\end{array}$ \\
\cline { 2 - 4 } & EC & State of other component & $\begin{array}{l}\text { Used when the cause of a failure is the result of a component state } \\
\text { that is not associated with the component that failed. For example, } \\
\text { a diesel failed due to no fuel in the fuel storage tanks. }\end{array}$ \\
\cline { 2 - 5 } & OT & Other & $\begin{array}{l}\text { Used when the cause of a failure is provided but it does not meet } \\
\text { any one of the descriptions. }\end{array}$ \\
\cline { 2 - 5 } & OK & Unknown & Used when the cause of the failure is not known. \\
\hline
\end{tabular}




\subsection{Existing Common-Cause Failure Data for Partial Alpha Factor Model Parameter Estimations}

While the previous subsection addresses the current CCF database classification system and recommends the using of failure cause groups for the PAFM due to the limited CCF data, this subsection searches the CCF database to find the observed CCF events for a specific component and failure mode. The data are then used to estimate the PAFM parameters (i.e., partial alpha factors and gamma factors).

Table 4-6 shows the EDG FTS failure events for each individual failure cause and CCF cause group. The data were obtained by searching the publicly accessible U.S. NRC database website, https://rads.inl.gov. (Note that the database website has a set of failure modes including FTS, FTR, fail-to-load, fail-to-open, fail-to-stop, and other failure modes. The failure modes on the website do not totally agree with those on the database output spreadsheet.) The website's Reliability tab was used to search for the total failure events while the CCF tab was used to search for the CCF events. The total failure events in Table 4-6 include both individual failure events and CCF events.

Table 4-6. Emergency diesel generator FTS failure events from rads.inl.gov.

\begin{tabular}{|c|c|c|c|c|c|}
\hline CCF Cause Group & Cause Code & \multicolumn{2}{|c|}{ Total Failure Events } & \multicolumn{2}{|c|}{ Total CCF Events } \\
\hline \multirow{3}{*}{$\begin{array}{c}\text { Component } \\
(\mathrm{GC})\end{array}$} & IC & 66 & \multirow[b]{3}{*}{100} & 2 & \multirow[b]{3}{*}{2} \\
\hline & IQ & 1 & & 0 & \\
\hline & IW & 33 & & 0 & \\
\hline \multirow{3}{*}{$\begin{array}{c}\text { Design } \\
(\mathrm{GD})\end{array}$} & DC & 0 & \multirow[b]{3}{*}{24} & 1 & \multirow[b]{3}{*}{1} \\
\hline & $\mathrm{DE}$ & 11 & & 0 & \\
\hline & $\mathrm{DM}$ & 13 & & 0 & \\
\hline \multirow{3}{*}{$\begin{array}{c}\text { Environment } \\
(\mathrm{GE})\end{array}$} & EA & 0 & \multirow[b]{3}{*}{7} & 0 & \multirow[b]{3}{*}{0} \\
\hline & $\mathrm{EE}$ & 0 & & 0 & \\
\hline & IE & 7 & & 0 & \\
\hline \multirow{4}{*}{$\begin{array}{c}\text { Human } \\
(\mathrm{GH})\end{array}$} & HA & 14 & \multirow[b]{4}{*}{40} & 0 & \multirow[b]{4}{*}{1} \\
\hline & HM & 17 & & 0 & \\
\hline & $\mathrm{HP}$ & 4 & & 0 & \\
\hline & PA & 5 & & 1 & \\
\hline \multirow{3}{*}{$\begin{array}{l}\text { Other } \\
(\mathrm{GO})\end{array}$} & $\mathrm{EC}$ & 0 & \multirow[b]{3}{*}{13} & 0 & \multirow[b]{3}{*}{0} \\
\hline & OT & 2 & & 0 & \\
\hline & $\mathrm{OK}$ & 11 & & 0 & \\
\hline \multicolumn{2}{|c|}{ Total } & 184 & 184 & 4 & 4 \\
\hline
\end{tabular}

For reasons of simplicity, it is assumed that the data in Table 4-6 represent a two-train EDG system, and each cause group could only propagate through one coupling factor. With the AFM that is currently used in the SPAR models, the alpha factors are calculated as:

$$
a_{1}=\frac{180}{184}=0.978
$$




$$
a_{2}=\frac{4}{184}=0.022
$$

With the PAFM, the partial alpha factors and gamma factors are determined as:

$$
\begin{array}{ll}
a_{2, G C}=\frac{2}{100}=0.020 & \gamma_{G C}=\frac{100}{184}=0.543 \\
a_{2, G D}=\frac{1}{24}=0.042 & \gamma_{G D}=\frac{24}{184}=0.130 \\
a_{2, G E}=\frac{0}{7}=0.000 & \gamma_{G E}=\frac{7}{184}=0.038 \\
a_{2, G H}=\frac{1}{40}=0.025 & \gamma_{G H}=\frac{40}{184}=0.217 \\
a_{2, G O}=\frac{0}{13}=0.000 & \gamma_{G O}=\frac{13}{184}=0.071
\end{array}
$$

Note that the above partial alpha factors can be converted back to alpha factors for use in CCBEs by summing up the contributions from each cause group or coupling factor:

$$
\begin{array}{ll}
\alpha_{2}^{\prime}=\sum_{i=1}^{5}\left(\alpha_{2, i} * \gamma_{i}\right)=0.022 & \alpha_{2}^{\prime}=a_{2} \\
\alpha_{1}^{\prime}=1-\alpha_{2}^{\prime}=0.978 & \alpha_{1}^{\prime}=a_{1}
\end{array}
$$

The results show that the assessed alpha factors, $\alpha_{2}^{\prime}$ and $\alpha_{1}^{\prime}$, in the PAFM have the same values as the alpha factors in the AFM. This is expected when the components in the CCCG are symmetrical and share the same coupling factors. This is also one of the reasons to select the PAFM as the alternate CCF model for implementation in the SPAR models. The alpha factors determined from the AFM could be used continuously in the SPAR base models while the partial alpha factors from the PAFM can be applied for an ECA.

\subsection{Generic Data for Prior Distribution}

Table 4-6 shows that the CCF data are so infrequent that even the generic data across the nuclear industry may have no observed CCF events for a specific component and failure mode. Two of the five cause groups have zero CCF events for the EDG FTS category. To alleviate the impact from the lack of $\mathrm{CCF}$ data, prior distribution (informative or non-informative) must be used when estimating the partial alpha factors for the model. The selection of the prior distribution can be a source that leads to large uncertainties on the assessment results. The O'Connor report [5] discusses several prior distributions such as population variability prior, priors based on expert opinion, uniform distribution, Jeffrey's prior distribution, and Novick and Hall's improper prior. This subsection looks at the generic data in the CCF database for two important failure modes: FTS and FTR.

Table 4-7 shows the FTS failure data for all components over different failure causes. Table 4-8 shows the FTR failure data for all components over different failure causes. Both failure data sets were obtained from the U.S. NRC database website https://rads.inl.gov. The website Reliability tab was used to search for total failure events while the CCF tab was used to search for CCF events. The total failure events in Table 4-7 and Table 4-8 include both individual failure events and CCF events. 
Table 4-7. All components fail-to-start failure events from rads.inl.gov.

\begin{tabular}{|c|c|c|c|c|c|}
\hline CCF Cause Group & Cause Code & \multicolumn{2}{|c|}{ Total Failure Events } & \multicolumn{2}{|c|}{ Total CCF Events } \\
\hline \multirow{3}{*}{$\begin{array}{l}\text { Component } \\
\text { (GC) }\end{array}$} & IC & 238 & \multirow[b]{3}{*}{368} & 9 & \multirow[b]{3}{*}{10} \\
\hline & IQ & 11 & & 0 & \\
\hline & IW & 119 & & 1 & \\
\hline \multirow{3}{*}{$\begin{array}{l}\text { Design } \\
\text { (GD) }\end{array}$} & DC & 6 & \multirow[b]{3}{*}{134} & 2 & \multirow[b]{3}{*}{8} \\
\hline & $\mathrm{DE}$ & 62 & & 3 & \\
\hline & DM & 66 & & 3 & \\
\hline \multirow{3}{*}{$\begin{array}{c}\text { Environment } \\
\quad(\mathrm{GE})\end{array}$} & EA & 18 & \multirow[b]{3}{*}{47} & 1 & \multirow[b]{3}{*}{1} \\
\hline & EE & 1 & & 0 & \\
\hline & IE & 28 & & 0 & \\
\hline \multirow{4}{*}{$\begin{array}{c}\text { Human } \\
(\mathrm{GH})\end{array}$} & HA & 44 & \multirow[b]{4}{*}{257} & 0 & \multirow[b]{4}{*}{5} \\
\hline & HM & 162 & & 1 & \\
\hline & HP & 31 & & 1 & \\
\hline & PA & 20 & & 3 & \\
\hline \multirow{3}{*}{$\begin{array}{l}\text { Other } \\
(\mathrm{GO})\end{array}$} & $\mathrm{EC}$ & 35 & \multirow[b]{3}{*}{534} & 4 & \\
\hline & OT & 11 & & 0 & \\
\hline & $\mathrm{OK}$ & 488 & & 0 & 4 \\
\hline \multicolumn{2}{|c|}{ Total } & 1,340 & 1,340 & 28 & 28 \\
\hline
\end{tabular}


Table 4-8. All components fail-to-run failure events from rads.inl.gov.

\begin{tabular}{|c|c|c|c|c|c|}
\hline CCF Cause Group & Cause Code & \multicolumn{2}{|c|}{ Total Failure Events } & \multicolumn{2}{|c|}{ Total CCF Events } \\
\hline \multirow{3}{*}{$\begin{array}{l}\text { Component } \\
\text { (GC) }\end{array}$} & IC & 163 & \multirow[t]{3}{*}{340} & 0 & \multirow[t]{3}{*}{3} \\
\hline & IQ & 20 & & 1 & \\
\hline & IW & 157 & & 2 & \\
\hline \multirow{3}{*}{$\begin{array}{c}\text { Design } \\
\text { (GD) }\end{array}$} & DC & 4 & \multirow[t]{3}{*}{172} & 0 & \multirow[t]{3}{*}{7} \\
\hline & $\mathrm{DE}$ & 100 & & 5 & \\
\hline & DM & 68 & & 2 & \\
\hline \multirow{3}{*}{$\begin{array}{l}\text { Environment } \\
\qquad(\mathrm{GE})\end{array}$} & EA & 19 & \multirow[t]{3}{*}{59} & 2 & \multirow[t]{3}{*}{8} \\
\hline & $\mathrm{EE}$ & 9 & & 2 & \\
\hline & IE & 31 & & 4 & \\
\hline \multirow{4}{*}{$\begin{array}{l}\text { Human } \\
(\mathrm{GH})\end{array}$} & $\mathrm{HA}$ & 44 & \multirow[t]{4}{*}{252} & 3 & \multirow[t]{4}{*}{6} \\
\hline & HM & 174 & & 1 & \\
\hline & HP & 26 & & 1 & \\
\hline & PA & 8 & & 1 & \\
\hline \multirow{3}{*}{$\begin{array}{l}\text { Other } \\
\text { (GO) }\end{array}$} & EC & 7 & \multirow[t]{3}{*}{834} & 3 & \multirow[t]{3}{*}{4} \\
\hline & OT & 13 & & 0 & \\
\hline & OK & 814 & & 1 & \\
\hline \multicolumn{2}{|c|}{ Total } & 1,657 & 1,657 & 28 & 28 \\
\hline
\end{tabular}

Applying the PAFM with the assumptions of a two-train system and symmetrical components that share the coupling factors, the generic PAFM parameters for a FTS failure mechanism are obtained as follows:

$$
\begin{array}{ll}
a_{2, G C}=\frac{10}{368}=0.027 & \gamma_{G C}=\frac{368}{1340}=0.275 \\
a_{2, G D}=\frac{8}{134}=0.060 & \gamma_{G D}=\frac{134}{1340}=0.100
\end{array}
$$




$$
\begin{aligned}
a_{2, G E} & =\frac{1}{47}=0.021 & \gamma_{G E} & =\frac{47}{1340}=0.035 \\
a_{2, G H} & =\frac{5}{257}=0.019 & \gamma_{G H} & =\frac{257}{1340}=0.192 \\
a_{2, G O} & =\frac{4}{534}=0.007 & \gamma_{G O} & =\frac{534}{1340}=0.399
\end{aligned}
$$

The above partial alpha factors are converted back to alpha factors for use in CCBEs by summing up the contributions from each cause group:

$$
\begin{gathered}
\alpha_{2}^{\prime}=\sum_{i=1}^{5}\left(\alpha_{2, i} * \gamma_{i}\right)=0.021 \\
\alpha_{1}^{\prime}=1-\alpha_{2}^{\prime}=0.979
\end{gathered}
$$

The generic PAFM parameters for the FTR failure mechanism are obtained as follows:

$$
\begin{array}{ll}
a_{2, G C}=\frac{3}{340}=0.009 & \gamma_{G C}=\frac{340}{1657}=0.205 \\
a_{2, G D}=\frac{7}{172}=0.041 & \gamma_{G D}=\frac{172}{1657}=0.104 \\
a_{2, G E}=\frac{8}{59}=0.0136 & \gamma_{G E}=\frac{59}{1657}=0.036 \\
a_{2, G H}=\frac{6}{252}=0.024 & \gamma_{G H}=\frac{252}{1657}=0.152 \\
a_{2, G O}=\frac{4}{834}=0.005 & \gamma_{G O}=\frac{834}{1657}=0.503
\end{array}
$$

The above partial alpha factors are converted back to alpha factors for use in CCBEs by summing up the contributions from each cause group:

$$
\begin{gathered}
\alpha_{2}^{\prime}=\sum_{i=1}^{5}\left(\alpha_{2, i} * \gamma_{i}\right)=0.017 \\
\alpha_{1}^{\prime}=1-\alpha_{2}^{\prime}=0.983
\end{gathered}
$$

The primary purpose of the above exercise was to illustrate that there are some data that might help inform the prior distributions for different failure modes. Further study is needed to determine whether this approach or any other approaches should be used to generate the priors. 


\section{IMPLEMENTING PARTIAL ALPHA FACTOR MODEL}

To implement the PAFM in the SPAR models, changes must be made to the following

- $\quad C C F$ database. A new CCF classification system that meets the PAFM requirement must be implemented. The process to collect and classify failure data must be reviewed and modified accordingly. The parameter estimation code must then be modified or rewritten to appropriately account for this change. New prior distributions must be developed to account for the different failure causes within a component group and failure mode for the PAFMs. Methods for scaling failure information (both alphas and gammas) to both larger and smaller component groups must be developed and implemented.

- SAPHIRE code. The software must be changed to include the PAFM parameters, calculate the nominal CCF probability, and perform different assessments as required (e.g., SDP, ECA). These changes require a new basic event structure to account for the additional parameters and internal probability calculation. The software change to handle the SDP or ECA requires additional questions on failure cause identified along with the component and failure mode to ensure correct conditional probability calculation.

- SPAR models. The SPAR models must be edited to couple the required new PAFM computational capability with model-input elements. Some of this could be coded into SAPHIRE to be automatic; however, there will still be manual verification and testing. Another area within the SPAR model update will be information about the coupling factors for each component and failure mode. This information may be absent for some of the components and assumptions may be necessary to incorporate the PAFM information into the SPAR model data. This requires agreement among the SPAR modeling team, Idaho National Laboratory (INL), and U.S. NRC on how to incorporate this information in a uniform and standardized approach.

- Guidelines for treating CCF in event assessments. The procedures and steps required to perform the different assessments utilizing the SPAR models and SAPHIRE must be updated when using the PAFM. This requires update of the "Risk Assessment of Operational Events Handbook" (RASP Handbook) [8] using the new CCF model in order for all analysts to consistently perform the analysis. Also, the modeling details and applications must be captured in related documentation and reports, including NRC training materials and SAPHIRE references.

\subsection{Common-Cause Failure Database}

As described in Subsection 4.1, the current CCF database is documented in NUREG/CR-6268 [3] and can be accessed through the U.S. NRC database website https://rads.inl.gov. The existing database classification system does not have a one-to-one relationship between the failure cause and coupling factor, which is one key assumption in the PAFM. The classification system must be revised to meet the PAFM requirement on the correlation between the failure cause and coupling factor. Table 4-4 presents the recommended classification system for use in the CCF database for the PAFM. Five CCF cause groups are suggested to estimate the PAFM parameters, rather than 10 or more individual failure causes, considering the scarce CCF data that are available. The current database classifications are closely relating these five failure cause groups and need little change. The coupling factor groups in Table 4-4 that correlate the failure cause groups are new to the database though, and must be incorporated into it. The process to collect and classify failure data should be reviewed and modified accordingly.

b The changed identified in this section have been worked on after the original report INL/LTD-14-33376 was published, for example, the developing of causal alpha factor priors, the guidelines for treating CCF in event assessment using the causal alpha factor model. Refer to associated NRC and INL papers or reports, such as INL/EXT-21-43723 (Revision 1 of INL/LTD-17-43723) [9]. 


\subsection{SAPHIRE Software}

To incorporate the PAFM into SAPHIRE, multiple changes are necessary. This subsection addresses restructuring the basic event input to include all of the events that will be used to calculate the CCF basic event and changing the CCF adjustment algorithm to correctly evaluate the CCF basic event when performing SDP or ECA calculations.

\subsubsection{SAPHIRE Basic Event Change}

The basic event module currently calculates the CCF basic event failure probability using the AFM. This module must be expanded to handle the different partial alpha factors and their corresponding gamma factors. The new basic event module will now take the new set of data inputs and calculate the CCF basic event probability. Figure 5-1 represents what an update to the basic event module might look like. The basic event module must have fields into which the partial alpha factors, along with their corresponding gamma factors, are placed. The basic event module would then take this information and calculate the CCF probability for the components of interest. All of this information is necessary for input into the new basic event module to perform event assessment. Having all of this information built directly into the basic event module allows for direct conditional probability calculation by selecting failure cause of interest. SAPHIRE now takes this information and, based on the conditional probability calculation, provides the new CCF probability for use in the assessment.

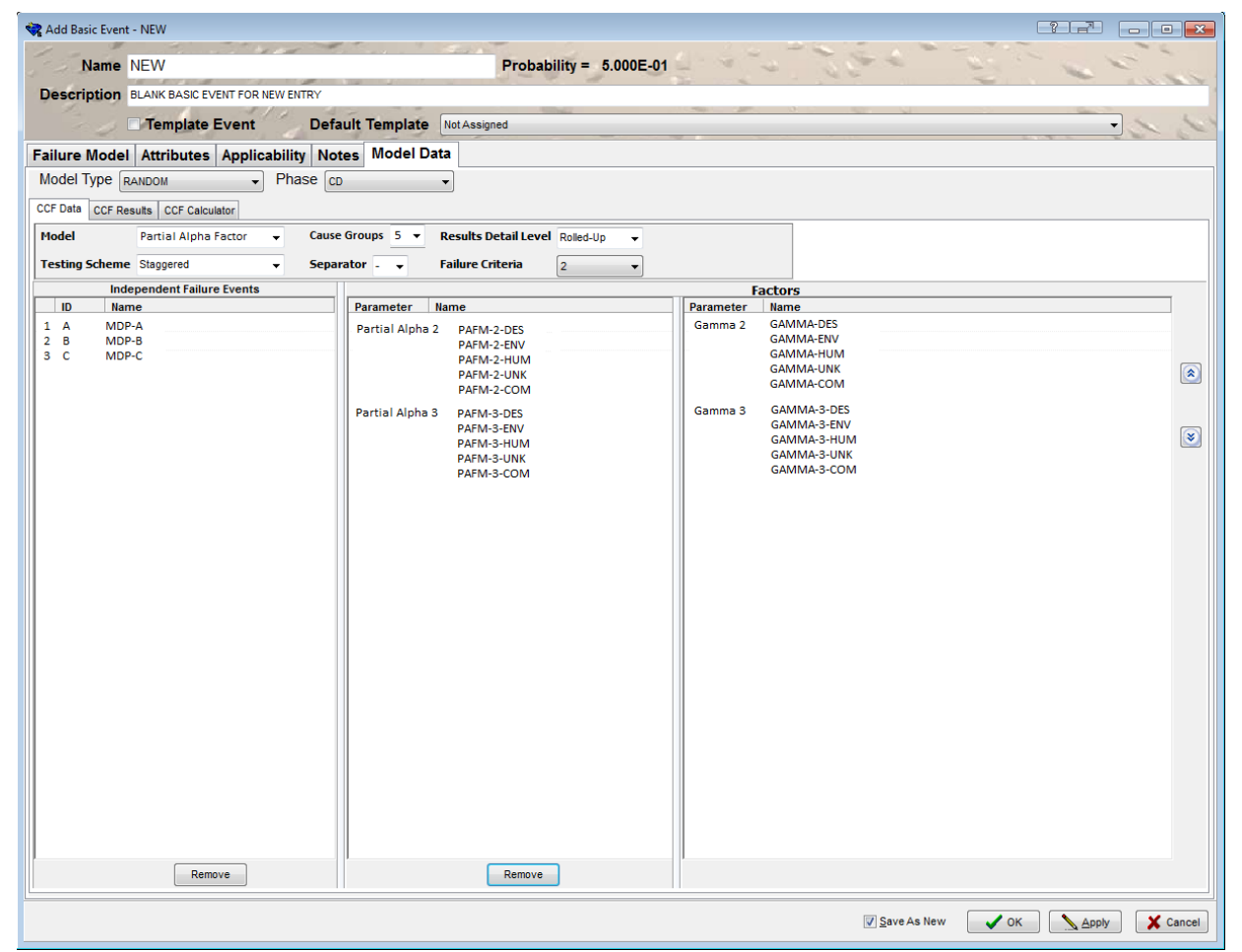

Figure 5-1. Possible updated basic event module.

\subsubsection{Partial Alpha Factor Model Parameter Estimation in SAPHIRE}

The PAFM in the O'Connor report [5] discusses the potential of modeling components into different CCCGs. However, this operation is not modeled within the SPAR models due to additional complexity and data collection. Therefore, the following example focuses on how the SPAR models incorporate the PAFM and perform event assessments conditioned on a failure. 
For this example, a three-train system is used, and only three different causes are included. As the failure causes increase, the mathematics also increases but the premise does not change. The three-train system cut sets are fully expanded based on the BPM (EE = environmental location, IP = installation procedures, and $\mathrm{MH}=$ maintenance staff):

$$
\begin{aligned}
& \mathrm{A}_{\mathrm{T}}=\mathrm{A}_{{ }_{\mathrm{I}}}+\mathrm{C}^{\prime}{ }_{\mathrm{AB}}+\mathrm{C}^{\prime}{ }_{\mathrm{AC}}+\mathrm{C}^{\prime}{ }_{\mathrm{ABC}} \\
& \mathrm{B}_{\mathrm{T}}=\mathrm{B}_{\mathrm{I}}+\mathrm{C}_{\mathrm{AB}}+\mathrm{C}_{\mathrm{BC}}+\mathrm{C}^{\prime}{ }_{\mathrm{ABC}} \\
& \mathrm{C}_{\mathrm{T}}=\mathrm{C}_{{ }_{\mathrm{I}}}+\mathrm{C}^{\prime}{ }_{\mathrm{BC}}+\mathrm{C}^{\prime}{ }_{\mathrm{AC}}+\mathrm{C}^{\prime}{ }_{\mathrm{ABC}} \\
& \mathrm{S}=\mathrm{A}^{\prime}{ }_{\mathrm{I}}{ }^{*} \mathrm{~B}^{\prime}{ }_{\mathrm{I}}{ }^{*} \mathrm{C}^{\prime}{ }_{\mathrm{I}}+\mathrm{A}^{\prime}{ }_{\mathrm{I}}{ }^{*} \mathrm{C}^{\prime}{ }_{\mathrm{BC}}+\mathrm{B}^{\prime}{ }_{\mathrm{I}}{ }^{*} \mathrm{C}^{\prime}{ }_{\mathrm{AC}}+\mathrm{C}^{\prime}{ }_{\mathrm{I}}{ }^{*} \mathrm{C}^{\prime}{ }_{\mathrm{AB}}+\mathrm{C}^{\prime}{ }_{\mathrm{ABC}}
\end{aligned}
$$

The reason for identifying the components and CCF parameters with the $A$ 'is to represent the averaged parameter using the PAFM. This averaged parameter takes the individual cause using the data and obtains the averaged alpha parameters for the modeling application. The following expresses each cause and then rolls it back up into the component for modeling and then illustrates how an assessment expands it back out to the individual failure cause.

The next step is to use the BPM model and determine the Q-terms for each of the individual events listed in the cut sets:

$$
\begin{aligned}
\mathrm{Q}_{1} & =\mathrm{A}_{\mathrm{I}} \\
\mathrm{Q}_{2} & =\mathrm{C}_{\mathrm{AB}}=\mathrm{C}_{\mathrm{AC}}=\mathrm{C}_{\mathrm{BC}} \\
\mathrm{Q}_{3} & =\mathrm{C}_{\mathrm{ABC}}
\end{aligned}
$$

To calculate the Q-terms, the following data (not real example data) are used to illustrate the application of this process. The O'Connor report [5] discusses the two ways to determine the parameter values: 1) maximum likelihood estimation (frequentist) and 2) Bayesian updated. The correct way and method that INL uses is the Bayesian updating approach. For this simple example, the maximum likelihood estimation is used. The data for the three different failure causes are:

$$
\begin{aligned}
& N_{\text {EE }}=[0,463,7,5] \\
& N_{\text {IP }}=[0,393,5,3] \\
& N_{M H}=[0,174,3,2]
\end{aligned}
$$

Given the data set above, the partial alpha factors are estimated using the maximum likelihood estimation:

$$
\begin{aligned}
& \alpha_{2, E E}=\frac{7}{463+7+5}=0.0147 \\
& \alpha_{2, I P}=\frac{5}{393+5+3}=0.0125 \\
& \alpha_{2, M H}=\frac{3}{174+3+2}=0.0168 \\
& \alpha_{3, E E}=\frac{5}{463+7+5}=0.0105 \\
& \alpha_{3, I P}=\frac{3}{393+5+3}=0.0075 \\
& \alpha_{3, M H}=\frac{2}{174+3+2}=0.0111
\end{aligned}
$$

The gamma factors for this set of data are:

$$
\gamma_{E E}=\frac{(463+7+5)}{(463+7+5)+(393+5+3)+(174+3+2)}=0.45
$$




$$
\begin{gathered}
\gamma_{I P}=\frac{(393+5+3)}{(463+7+5)+(393+5+3)+(174+3+2)}=0.38 \\
\gamma_{M H}=\frac{(174+3+2)}{(463+7+5)+(393+5+3)+(174+3+2)}=0.17
\end{gathered}
$$

To use this information to calculate the different Q-terms in the example (assuming staggered testing scheme), the basic events for each component are:

$$
Q_{1}^{(3)}=\alpha_{1}^{\prime} Q_{t}, \quad Q_{2}^{(3)}=\frac{1}{2} \alpha_{2}^{\prime} Q_{t}, \quad Q_{3}^{(3)}=\alpha_{3}^{\prime} Q_{t}
$$

Assuming the components are perfectly symmetrical, the assessed alpha factors have a contribution from all coupling factors:

$$
\begin{gathered}
\alpha^{\prime}{ }_{3}=\sum_{i=\{I P, M H, E E\}} \gamma_{i} \alpha_{3, i}=0.00948 \\
\alpha^{\prime}{ }_{2}=\sum_{i=\{I P, M H, E E\}} \gamma_{i} \alpha_{2, i}=0.0142 \\
\alpha^{\prime}{ }_{1}=1-\alpha^{\prime}{ }_{2}-\alpha^{\prime}{ }_{3}=0.976
\end{gathered}
$$

To determine $Q_{t}$, the total number of demands and total number of failures are determined from the number of failures and assumed $Q_{t}$. For this example, it is assumed there was a total of 180,000 demands on the system. This gives the total number of 1,090 failures. The following equation is used to determine $Q_{t}$ :

$$
Q_{t}=\frac{1030+(2 * 15)+(3 * 10)}{3 *(180,000+1030+15+10)}=2.01 E-3
$$

The Q-terms that are used in the BPM are calculated using the PAFM information above and the staggered testing scheme. These events are used for the assessment examples as follows: ${ }^{\mathrm{c}}$

$$
\begin{gathered}
Q_{1}^{(3)}=\alpha^{\prime}{ }_{1} Q_{t}=0.976 * 2.01 E-3=1.96 E-03 \\
Q_{2}^{(3)}=\frac{1}{2} \alpha_{2}^{\prime} Q_{t}=\frac{1}{2} * 0.0142 * 2.01 E-3=1.43 E-05 \\
Q_{3}^{(3)}=\alpha^{\prime}{ }_{3} Q_{t}=0.00948 * 2.01 E-3=1.90 E-05
\end{gathered}
$$

Using this information, the probability for the example three-train system is as follows:

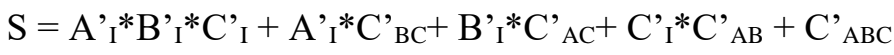

$$
\begin{aligned}
& \mathrm{P}(\mathrm{S})=\left(\mathrm{Q}_{1}\right)^{\wedge} 3+3 * \mathrm{Q}_{2} * \mathrm{Q}_{1}+\mathrm{Q}_{3} \\
& =(1.96 \mathrm{E}-3)^{\wedge} 3+3 * 1.43 \mathrm{E}-05 * 1.96 \mathrm{E}-03+1.90 \mathrm{E}-05=1.91 \mathrm{E}-05
\end{aligned}
$$

So far, this process is the same as for the AFM, which is already built into the current SPAR models. The difference between the two models is in the identification and quantification of the partial alpha factors that are rolled up and used as the overall alpha factors and how the PAFM is used when performing event assessment.

\subsubsection{Condition Assessment with Partial Alpha Factor Model}

This subsection describes conditional CCF calculations for the following boundary conditions:

- Observed failure of one component in the CCCG with the potential for a shared cause

- Observed failure of one component in the CCCG without the potential for a shared cause

\footnotetext{
${ }^{\mathrm{c}}$ Note that the rounding off in intermediate steps of the calculations may lead to slightly different results.
} 
- Observed unavailability of one or more components in the CCCG due to testing or planned maintenance.

This subsection also provides the process that would be performed to obtain the conditional probability based on subsets of system cut sets. These cases are for illustration purposes.

\subsubsection{Observed failure of one component in common-cause component group with potential for shared cause}

The failure combinations for a three-train system are:

$$
\mathrm{S}=\left\{\left(A_{I}^{\prime} \cap B_{I}^{\prime} \cap C_{I}^{\prime}\right) \cup\left(A_{I}^{\prime} \cap C_{B C}^{\prime}\right) \cup\left(B_{I}^{\prime} \cap C_{A C}^{\prime}\right) \cup\left(C_{I}^{\prime} \cap C_{A B}^{\prime}\right) \cup C_{A B C}^{\prime}\right\}
$$

The definition of "A total" is (B total and $\mathrm{C}$ total are similar):

$$
A_{t}^{\prime}=A_{I}^{\prime} \cup C_{A B}^{\prime} \cup C_{A C}^{\prime} \cup C_{A B C}^{\prime}
$$

When a failure is observed with the potential for a shared cause, this implies that the conditioning is on "A total." Returning to the definition of a conditional probability, the equation is:

$$
\operatorname{Pr}\left(S \mid A_{t}^{\prime}\right)=\frac{\operatorname{Pr}\left(S \cap A_{t}^{\prime}\right)}{\operatorname{Pr}\left(A_{t}^{\prime}\right)}
$$

where (we are only interested in the CCF terms because the independent terms are modeled in the fault tree and handled via software)

$$
\begin{aligned}
S \cap A_{t}^{\prime}= & \left\{A_{I}^{\prime} C_{B C}^{\prime}, B_{I}^{\prime} C_{A C}^{\prime}, C_{I}^{\prime} C_{A B}^{\prime}, C_{A B C}^{\prime}\right\} \\
\therefore \operatorname{Pr}\left(S \mid A_{t}^{\prime}\right)= & \frac{\operatorname{Pr}\left(S \cap A_{t}^{\prime}\right)}{P_{r}\left(A_{t}^{\prime}\right)}=\frac{3\left(\alpha_{1}^{\prime} Q_{t}\right) \cdot\left(\frac{1}{2} \alpha_{2}^{\prime} Q_{t}\right)+\alpha_{3}^{\prime} Q_{t}}{\alpha_{1}^{\prime} Q_{t}+\frac{1}{2} \alpha_{2}^{\prime} Q_{t}+\frac{1}{2} \alpha_{2}^{\prime} Q_{t}+\alpha_{3}^{\prime} Q_{t}} \\
& =\frac{\frac{3}{2}\left(\alpha_{1}^{\prime} Q_{t}\right) \cdot\left(\alpha_{2}^{\prime} Q_{t}\right)+\alpha_{3}^{\prime} Q_{t}}{\left(\alpha_{1}^{\prime}+\alpha_{2}^{\prime}+\alpha_{3}^{\prime}\right) Q_{t}} \\
& =\frac{3}{2} \alpha_{1}^{\prime} \cdot \alpha_{2}^{\prime} Q_{t}+\alpha_{3}^{\prime}
\end{aligned}
$$

Substituting in parameter values gives:

$$
\operatorname{Pr}\left(S \mid A_{t}^{\prime}\right)=\frac{3}{2} * 0.976 * 0.0142 * 2.01 E-3+0.00948=9.52 E-3
$$

The process illustrated above is the same when using the PAFM with the only difference coming from evaluating the actual failure cause versus the overall (weighted average) alpha parameters.

To represent this example, the first task is to illustrate each of the failure causes and how they apply to the BPM. The group of cut sets in Equation 31 is evaluated based on a specific cause and how the conditional probability is determined. The definition of "A total" is:

$$
\begin{gathered}
A_{t}^{\prime}=A_{I}^{\prime} \cup C_{A B}^{\prime} \cup C_{A C}^{\prime} \cup C_{A B C}^{\prime} \\
A_{I}^{\prime}=B_{I}^{\prime}=C_{I}^{\prime}=Q_{t} *\left(\gamma_{E E} \alpha_{1, E E}+\gamma_{I P} \alpha_{1, I P}+\gamma_{M H} \alpha_{1, M H}\right) \\
C_{A B}^{\prime}=C_{A C}^{\prime}=C_{B C}^{\prime}=Q_{t} *\left(\gamma_{E E} \alpha_{2, E E}+\gamma_{I P} \alpha_{2, I P}+\gamma_{M H} \alpha_{2, M H}\right)
\end{gathered}
$$

The overall cut sets are combinations of each failure cause "ANDed" with the other failure causes for each component. To illustrate these combinations, the A-train component of a three-train system is used to expand out the different combinations. These are the same for the other two trains (B and $\mathrm{C}$ ) of the three-train system.

$$
A_{I, E E} \cap\left\{\left[\left(B_{I, E E} \cap C_{I, E E}\right) \cup C_{B C, E E}\right] \cup\left[\left(B_{I, I P} \cap C_{I, I P}\right) \cup C_{B C, I P}\right] \cup \ldots . .\right\}
$$


To perform an event assessment using a specific failure cause and the cut sets above-excluding the independent failures because these are handled automatically within the software and fault tree modeling - the following information is provided.

For this example, it is assumed that the cause identified was an installation procedure. This specific failure cause is propagated through the cut sets to obtain the resultant set, and then the conditional probability is calculated. To start this event assessment, the gamma factor for IP is set to 1.0 and the gamma factor for the other two failure causes is set to zero because the failure cause is known. This reduces the cut sets based on just the common-cause contribution (how SPAR/SAPHIRE will evaluate) down to just:

$$
\begin{gathered}
S \cap A_{t, I P}=\left\{\left(A_{I, I P} \cap C_{B C, I P}\right) \cup\left(B_{I, I P} \cap C_{A C, I P}\right) \cup\left(C_{I, I P} \cap C_{A B, I P}\right) \cup C_{A B C, I P}\right\} \\
\begin{array}{c}
P r\left(S \mid A_{t, I P}\right)==\frac{\operatorname{Pr}\left(S \cap A_{t, I P}\right)}{P_{r}\left(A_{t, I P}\right)}=\frac{3\left(\alpha_{1, I P} Q_{t}\right) \cdot\left(\frac{1}{2} \alpha_{2, I P} Q_{t}\right)+\alpha_{3, I P} Q_{t}}{\alpha_{1, I P} Q_{t}+\frac{1}{2} \alpha_{2, I P} Q_{t}+\frac{1}{2} \alpha_{2, I P} Q_{t}+\alpha_{3, I P} Q_{t}} \\
=\frac{3}{2} \alpha_{1, I P} \cdot \alpha_{2, I P} Q_{t}+\alpha_{3, I P}
\end{array}
\end{gathered}
$$

Substituting in parameter values gives:

$$
\begin{gathered}
\alpha_{1, I P}=1-\alpha_{2, I P}-\alpha_{3, I P}=1-0.0125-0.0075=0.98 \\
P r\left(S \mid A_{t, I P}\right)=\frac{3}{2} * 0.98 * 0.0125 * 2.01 E-3+0.0075=7.54 E-3
\end{gathered}
$$

Using the same process could obtain the results for other causes: $\operatorname{Pr}\left(S \mid A_{t, \mathrm{EE}}\right)=1.06 E-2$ and $\operatorname{Pr}\left(S \mid A_{t, \mathrm{MH}}\right)=1.12 E-3$. These condition assessment results with PAFM can be compared to the result with AFM in Equation 87, $\operatorname{Pr}\left(S \mid A_{t}^{\prime}\right)=9.52 E-3$.

\subsubsection{Observed failure of one component in common-cause component group without potential for shared cause}

The failure combinations for a three-train system are:

$$
\mathrm{S}=\left\{\left(A_{I}^{\prime} \cap B_{I}^{\prime} \cap C_{I}^{\prime}\right) \cup\left(A_{I}^{\prime} \cap C_{B C}^{\prime}\right) \cup\left(B_{I}^{\prime} \cap C_{A C}^{\prime}\right) \cup\left(C_{I}^{\prime} \cap C_{A B}^{\prime}\right) \cup C_{A B C}^{\prime}\right\}
$$

When a failure is observed without the potential for a shared cause (i.e., an independent failure), this implies that the conditioning is on "A independent." From the definition of a conditional probability, the equation becomes:

$$
\operatorname{Pr}\left(S \mid A_{I}\right)=\frac{\operatorname{Pr}\left(S \cap A_{I}^{\prime}\right)}{\operatorname{Pr}\left(A_{I}^{\prime}\right)}
$$

where (we are only interested in the CCF terms, since the independent terms are modeled in the fault tree and handled via software)

$$
\begin{gathered}
S \cap A_{I}^{\prime}=\left\{A_{I}^{\prime} C_{B C}^{\prime}\right\} \\
\therefore \operatorname{Pr}\left(S \mid A_{I}^{\prime}\right)=\left(\frac{\alpha_{1}^{\prime} Q_{t} \cdot 1 / 2 \alpha_{2}^{\prime} Q_{t}}{\alpha_{1}^{\prime} Q_{t}}\right) \\
=1 / 2 \alpha_{2}^{\prime} Q_{t}
\end{gathered}
$$

Substituting in parameter values gives:

$$
\operatorname{Pr}\left(S \mid A_{I}^{\prime}\right)=\frac{1}{2} * 0.0142 * 2.01 E-3=1.43 E-05
$$

The process illustrated above is exactly the same when using the PAFM to evaluate the event. Given the assumption that the failure is independent, the causes for the train that failed all become zero, and the 
CCF potential that is left is between the two remaining trains. That is why the resultant CCF term becomes the CCF between the remaining two trains.

\subsubsection{The test and maintenance case}

For the test and maintenance case, the condition is that one component in a three-train system is out of service for preventive maintenance or testing. In this example, the three-train system uses the same component designation as above (A, B, and $\mathrm{C}$ ) and a one-of-three success criterion. It is assumed that Component $\mathrm{A}$ is unavailable due to preventive maintenance and that it is not in a failed state (as it would be if the maintenance outage were for corrective maintenance). Although Component A is out for preventive maintenance, and thus cannot itself fail, the potential exists for causes and coupling factors still to be shared between Component $\mathrm{A}$ and the other components in the common-cause group. That is, $\mathrm{C}_{\mathrm{AB}}, \mathrm{C}_{\mathrm{AC}}$, and $\mathrm{C}_{\mathrm{ABC}}$ have not occurred, but they could occur. Events $\mathrm{C}_{\mathrm{AC}}$ and $\mathrm{C}_{\mathrm{ABC}}$ now represent causes that have the potential to fail Components $\mathrm{A}$ and $\mathrm{C}$, or $\mathrm{A}, \mathrm{B}$, and $\mathrm{C}$, respectively.

Because Component $\mathrm{A}$ is unavailable, but not failed, the conditioning term to be used in the test and maintenance calculations is a/AI. That is, we condition on NOT seeing Train A failed (it is simply out for test and maintenance).

Quantification of these cut sets in terms of the BPM (and the staggered AFM) yields:

Observe $/ A_{I}$

$$
\begin{gathered}
S \cap\left(/ A_{I}\right)=\left\{/ A_{I} B_{I} C_{A C}, / A_{I} C_{I} C_{A B}, / A_{I} C_{A B C}\right\} \\
\therefore P_{r}\left(S \mid \overline{A_{I}}\right)=\frac{\overline{Q_{1}} Q_{1} Q_{2}}{\overline{Q_{1}}}+\frac{\overline{Q_{1}} Q_{1} Q_{2}}{\overline{Q_{1}}}+\frac{\overline{Q_{1}} Q_{3}}{\overline{Q_{1}}} \\
=2 Q_{1} Q_{2}+Q_{3} \\
=2 \alpha_{1}^{\prime} Q_{t} * 1 / 2 \alpha_{2}^{\prime} Q_{t}+\alpha_{3}^{\prime} Q_{t}
\end{gathered}
$$

Substituting in parameter values gives:

$$
\begin{gathered}
\operatorname{Pr}\left(S \mid \overline{A_{I}}\right)=(2 * 0.976 * 2.01 E-3) *(0.5 * 0.0142 * 2.01 E-3)+(0.00948 * 2.01 E-3) \\
=1.91 E-05
\end{gathered}
$$

\subsection{Common-Cause Failure Treatment Guidelines}

Section 5 of the RASP Handbook [8] provides guidance for treating CCF dependencies that U.S. NRC staff should use when performing risk assessments of operational events and licensee performance issues. With the implementation of the cause-based CCF model, new guidance for treating CCFs with the PAFM in event assessments should be developed. 


\section{SUMMARY}

This report is a revision of the original report, INL/LTD-14-33376. Distribution of the original report was limited to the NRC only, and the report was not made available to the public. The original report was revised as this report for public distribution. The report presents the feasibility study of the development of alternative CCF models for event assessment using the SPAR models. While the AFM has been widely utilized in PRA, including the SPAR models, for many years, it is recognized that some issues, and potential improvements, exist in the state-of-the-practice CCF modeling. This report investigates whether two alternative CCF models, PAFM and GDM, could be used to replace the AFM as the standard model for event assessment using the SPAR models. The alternative models were reviewed and compared with their strengths and weaknesses.

After the review, the PAFM appears to be the best choice as the alternate CCF model to replace the AFM currently used in SPAR models. The PAFM contains more detail than the AFM, which will make event assessments more straightforward. The partial alpha factors relate to causes that are expected to align well with those most often seen in event assessment. The analyst will have to identify the cause of a component failure that will set the specific gamma parameter to 1.0 and all others to zero. The resulting conditional probability of CCF potential will be conditioned on the occurrence of the identified cause. This CCF modeling for event assessment could then eliminate some of the conservatisms built into the AFM. The current AFM is not causal and does not incorporate causes of failure explicitly while the reality is that conditional probabilities associated with different causes may differ significantly.

The PAFM is also the easier model to incorporate into SAPHIRE and the SPAR models because (1) most of the structure is in place in the software from the AFM and (2) the basic events are already modeled, and only data changes into the basic events are required once the software has been updated. Therefore, no fault tree logic-structure changes are necessary.

The GDM has some advantages over the PAFM, based on its underlying structure and the ability to update conditional and system probabilities based on new evidence. The GDM structure using the Bayesian Network lends itself directly to event assessment because all of the potential conditions are modeled explicitly. Therefore, when events occur, they can be directly modeled into the structure, and the overall probability is calculated based on this new set of evidence. However, the complexity of software development, data collection, and implementation into fault tree logic models prohibits the practical use of the GDM in SPAR models.

To implement the PAFM in the SPAR models, changes must be made to the following:

- $\quad C C F$ database. A new CCF classification system that meets the PAFM requirement must be implemented. The process to collect and classify failure data must be reviewed and modified accordingly. The parameter estimation code must then be modified or rewritten to appropriately account for this change. New prior distributions must be developed to account for the different failure causes within a component group and the failure mode for the PAFMs. Methods for scaling failure information (both alphas and gammas) to both larger and smaller component groups must be developed and implemented.

- SAPHIRE code. The software must be changed to include the PAFM parameters, calculate the nominal CCF probability, and perform different assessments as required (e.g., SDP, ECA). These changes require a new basic event structure to account for the additional parameters and internal probability calculation. The software change to handle the SDP or ECA requires additional questions on failure cause identified, along with the component and failure mode to ensure correct conditional probability calculation. 
- SPAR models. The SPAR models must be edited to couple the required new PAFM computational capability with model-input elements. Some of this could be coded into SAPHIRE to be automatic; however, there will still be manual verification and testing. Another area within the SPAR model update will be information about the coupling factors for each component and failure mode. This information may be absent for some of the components, and assumptions may be necessary to incorporate the PAFM information into the SPAR model data. This requires agreement among the SPAR modeling team, INL, and U.S. NRC on how to incorporate this information in a uniform and standardized approach.

- Guidelines for treating CCF in event assessments. The procedures and steps required to perform the different assessments utilizing the SPAR models and SAPHIRE must be updated when using the PAFM. This requires update of the RASP Handbook [8] using the new CCF model in order for all analysts to consistently perform the analysis. Also, the modeling details and applications must be captured in related documentation and reports, including NRC training materials and SAPHIRE references.

The changes identified in this section have been worked on after the original report INL/LTD-1433376 was published, for example, the development of causal alpha factor priors and the guidelines for treating CCF in event assessments using the causal alpha factor model. Refer to associated NRC and INL papers or reports, such as INL/EXT-21-43723 (Revision 1 of INL/LTD-17-43723) [9]. 


\section{REFERENCES}

[1] Pickard, Lowe, and Garrick, Inc., "Procedures for Treating Common Cause Failures in Safety," United States Nuclear Regulatory Commission, NUREG/CR 4780, January 1988.

[2] Mosleh, D. Rasmuson, F. Marshall, "Guidelines on Modeling Common Cause Failures in Probabilistic Risk Assessment," United States Nuclear Regulatory Commission, NUREG/CR 5485, November 1998.

[3] T. Wierman, D. Rasmuson and A. Mosleh, "Common Cause Failure Database and Analysis System: Event Data Collection, Classification, and Coding," United States Nuclear Regulatory Commission, NUREG/CR 6268, Revision 1, September 2007.

[4] Mosleh, K. Coyne, C. Hunter, S. Shen, "Basis for the Treatment of Potential Common-Cause Failure in the Significance Determination Process", United States Nuclear Regulatory Commission, NUREG-2225, 2018

[5] N. O'Connor and A. Mosleh, "A General Cause Based Methodology for Analysis of Dependent Failures in System Risk and Reliability Assessments," United States Nuclear Regulatory Commission, (NRC-04-10-164), July 2013.

[6] Smith and S. T. Wood, "Systems Analysis Programs for Hands on Integrated Reliability Evaluations (SAPHIRE) Version 8," United States Nuclear Regulatory Commission, NUREG/CR 7039, June 2011.

[7] K. Fleming, A. Mosleh and R. K. Deremer, "A systematic procedure for the incorporation of common cause events into risk and reliability models," Nuclear Engineering and Design, vol. 93, no. 2 3, pp. 245 273, May 1986.

[8] U. S. Nuclear Regulatory Commission, "Risk Assessment of Operational Events Handbook," Volume 1 Internal Events, Revision 2.0, United States Nuclear Regulatory Commission, January 2013.

[9] Z. Ma and J. Schroeder, "Developing Generic Prior Distributions for Common Cause Failure Alpha Factors and Causal Alpha Factors," Idaho National Laboratory, INL/EXT-21-43723, Revision 1 of INL/LTD-17-43723, July 2021. 


\section{APPENDIX A}

\section{DEFINITIONS}

Common-cause component group (CCCG). As defined in NUREG/CR-4780, "A group of (usually similar) components that are considered to have a high potential of failing due to the same cause." The definition is revised slightly to say simply that the components share a potential for failing due to the same cause; the potential for failure does not need to be high. In fact, with typical values, in a CCCG of size two, if a failure of one component is observed, the conditional probability that the second component will fail due to the same cause is $<0.05$.

Common-cause failure. The potential of two or more components to fail within a probabilistic risk assessment mission time window as a result of a shared cause. Note that the failure mechanisms do not have to be shared. Further, the subcomponent or piece parts that fail do not have to be the same.

Common-mode failure. A term used in the WASH-1400 Report ${ }^{\mathrm{e}}$ to describe dependent failures of all kinds. This term was later modified in various ways, which has led to confusion. Due to the confusion, use of this term is discouraged when discussing common-cause failures.

Dependent failure. The joint probability of two or more components failing is not equal to the product of the individual probabilities of failure. Dependent failures do not have to be simultaneous.

Independent failure. Two events are statistically independent if the occurrence of one event does not change the probability of occurrence of the other. The mathematical definition of independent events is $P(A \cap B)=P(A) \cdot P(B)$.

Individual failure. A failure of a single component in a CCCG of size $m$.

d Pickard, Lowe, and Garrick, Inc., "Procedures for Treating Common Cause Failures in Safety," United States Nuclear Regulatory Commission, NUREG/CR-4780, January 1988.

e Reactor Safety Study, “An Assessment of Accident Risks in U.S. Commercial Nuclear Power Plants," WASH-1400, United States Nuclear Regulatory Commission, October 1975. 